Article

\title{
Effect of the Asphaltene Oxidation Process on the Formation of Emulsions of Water in Oil (W/O) Model Solutions
}

\author{
Sebastián Llanos ${ }^{1}$, Sócrates Acevedo ${ }^{2}$, Farid B. Cortés ${ }^{1, *}$ and Camilo A. Franco ${ }^{1, *}$ \\ 1 Grupo de Investigación Fenómenos de Superficie-Michael Polanyi, Facultad de Minas, Universidad \\ Nacional de Colombia Sede Medellín, Kra 80 No. 65-223, 050034 Medellín, Colombia; sllanosg@unal.edu.co \\ 2 Facultad de Ciencias, Centro de Química Orgánica, Universidad Central de Venezuela, P.O. Box 47102, \\ Caracas 7020-A, Venezuela; socrates.acevedo@gmail.com \\ * Correspondence: fbcortes@unal.edu.co (F.B.C.); caafrancoar@unal.edu.co (C.A.F.); Tel.: +57-4-425-5137 (F.B.C.); \\ $+57-4-425-4313$ (C.A.F.)
}

Received: 5 February 2018; Accepted: 15 March 2018; Published: 22 March 2018

\begin{abstract}
In this paper, the formation of water in oil (W/O) model solution emulsions using untreated and oxidized asphaltenes as emulsifiers was evaluated. Emulsions were formed with deionized water and toluene at different water/toluene ratios (1:4, 1:1, and 4:1) and concentrations of asphaltenes of 100, 500, and $1000 \mathrm{mg} / \mathrm{L}$. Asphaltenes were oxidized at two different temperatures of 373 and $473 \mathrm{~K}$ for various exposure times. Untreated and oxidized asphaltenes were characterized by thermogravimetric analyses, C, H, N, S and O elemental analyses, solvency tests in toluene, and qualitative structural indexes from Fourier-transform infrared spectroscopy. The emulsions were evaluated for stability, the percentage of oil in water $(\mathrm{O} / \mathrm{W})$ and $\mathrm{W} / \mathrm{O}$ phases, interfacial tension (IFT), and mean droplet diameter. The asphaltenes solubility decreased up to $93 \%$ as the temperature of oxidation and the exposure time increased. The amount of $\mathrm{W} / \mathrm{O}$ emulsion increases when asphaltene concentration, exposure time, and oxidation temperature increase. With oxidized asphaltenes at 373 and $473 \mathrm{~K}$, the formation of W/O emulsions increased by approximately $30 \%$ and $70 \%$ for a fixed asphaltene concentration, respectively. IFT revealed that after oxidation, no carboxylic acids were formed. A hypothetical oxidation reaction of asphaltenes to ketones and sulphoxide, and nitrogen and alkyl chain removal is proposed.
\end{abstract}

Keywords: asphaltenes; heavy oil; oxidation; thermal EOR; W/O emulsions

\section{Introduction}

Due to the increasing global energy demand and depletion of conventional sources of energy, the oil and gas industry has paid particular attention to the exploration and production of heavy (HO) and extra-heavy crude oils (EHO) [1]. The highest percentage of the world's oil resources corresponds to these type of crude oils that have high complexity for production, transport, and refining due to their high viscosities, which increase dramatically with the asphaltenes content [2]. For this reason, oil companies are seeking technological innovations to facilitate and make more profitable the production and refining of this type of unconventional hydrocarbons. Different enhanced oil recovery (EOR) techniques are employed to increase $\mathrm{HO}$ and $\mathrm{EHO}$ production, either cold (at reservoir temperature) or thermal by inducing heat to the reservoir. The choice of optimal EOR method requires an analysis of fluid properties, reservoir, and production system [1]. Cold techniques such as solvent-drive mechanisms, chemical flooding, and miscible displacements are used to reduce the oil viscosity and improve the sweep efficiency in the reservoir, respectively. Moreover, different thermal EOR methods are applied when cold 
techniques are not efficient and include in-situ combustion (ISC), steam drive, cyclic steam stimulation (CSS), steam-assisted gravity drainage (SAGD), electrical heating, among others [3,4].

The principal mechanism for thermal EOR applications consists in the viscosity reduction of $\mathrm{HO}$ and EHO through heat induction, as well as molecular diffusion, mass transfer, capillary forces and, in some cases upgrading of the crude oils, mainly in ISC processes [5-7]. Although the use of in-situ combustion may lead to increasing of the recovery factor up to $30 \%$, the chemical reactions of the high molecular weight and more polar hydrocarbons with the injected air may lead to the formation of very strong emulsions, which affect the economics of the operation due to the difficulty in the emulsion management and breaking [8-10]. The formation of $\mathrm{W} / \mathrm{O}$ and $\mathrm{O} / \mathrm{W}$ emulsions is one of the challenges to overcome as large amounts of water and oil accompany the production of $\mathrm{HO}$ and $\mathrm{EHO}$, where approximately $65 \%$ or more of the oil produced is emulsified [11-15]. Emulsions present problems at different stages such as production, transporting, and treatment, having a significant impact on the efficiency and economy of an EOR process [16,17]. The presence of water as a dispersed phase in the crude oil increases drastically the oil viscosity and also may lead to the blockage of the porous medium [18,19], which is reflected on the surface with high-pressure drops in the flow and production lines, as well as reduction of the production rate [20]. Emulsifying agents that contribute to the formation of emulsions are asphaltenes, resins, organic acids, waxes, clays, among others $[17,21]$. However, in HO and EHO reservoirs, asphaltenes are of particular importance due to the high content and their particular physicochemical characteristics. Asphaltenes are polar and high molecular weight compounds in colloidal dispersion in oil, containing heteroatoms such as $\mathrm{N}, \mathrm{O}$, and $\mathrm{S}$. Their location in the molecular structure gives the asphaltenes high polarity and an amphiphilic character, i.e., its structure has different functional groups with polar and nonpolar selectivity [22]. In the emulsions formation, the accumulation of asphaltenes at the water-oil interface forms a rigid film that directly influences the stability of the emulsion and prevents droplet coalescence of the dispersed phase [23,24]. According to Rane et al. [25-28], asphaltenes form a film at the water-oil interface where asphaltene are adsorbed and form a stable multilayer that prevents separation of the immiscible phases. Because of their high polarity, asphaltenes can self-associate and be found at the water-oil interface as large aggregates, influencing the stabilization of the emulsions [29]. The stability of the emulsion is related to the concentration of the asphaltenes in the crude oil, but also its colloidal dispersion is a critical variable to establish the stiffness or hardness of the interfacial layer and its contribution to the stability [30]. Hence, when the emulsion is stable, low values in the compressibility of the interfacial layer are observed since the coalescence of the drops requires compression of the $\mathrm{W} / \mathrm{O}$ interface [26]. These low compressibility values in the interfacial film indicate that their viscoelastic characteristics are a consequence of a film of asphaltenes adsorbed at the interface [31]. Different physicochemical properties of asphaltenes such as aromaticity, a short length of side alkyl chains, reduction of branching in aliphatic chains, an increase in the number of aromatic rings, and the presence of carbonyl groups show a clear trend for asphaltenes to form stable emulsions [29,32]. Hence, physicochemical changes in asphaltene structure during thermal EOR recovery processes may worsen the emulsification process $[33,34]$. In this way, in the field trial for ISC that was implemented in the Quifa Field located on the eastern plains of Colombia an emulsion problem was observed $[35,36]$. The field trial was planned in three stages: an initial cold production stage, followed by a preheating stage, and finally a heat production stage. The formation of emulsions in the field trial led to substantial operational problems, due to its stabilization during air injection, leading to clogging of the production system and increasing the operational costs to obtain the crude oil in sales specifications. These problems were solved after testing different chemicals applied to the well and surface equipment [37].

However, the phenomenology of the issue of emulsification after asphaltenes undergo a thermal process such as air injection at temperatures higher than reservoir conditions is still not fully understood. Hence, the primary objective of this work is to evaluate the effect of physicochemical changes in asphaltene molecule after oxidation in the formation of W/O emulsions using heavy and extra-heavy oil model solutions. Changes in the asphaltene molecule after the thermal treatment at 373 and $473 \mathrm{~K}$ were evaluated through elemental analyses, solvency tests, Fourier transform infrared 
spectroscopy (FTIR), and thermogravimetric analyses (TGA). The feasibility of thermally treated asphaltenes in the formation of $\mathrm{W} / \mathrm{O}$ emulsions was evaluated for asphaltenes with different exposure time to air flow, different concentrations and different model solution to water ratios. It is expected that this work provides a wider landscape about the effect of asphaltene in the emulsification of heavy and extra-heavy oils during thermal EOR processes and hence a better control of the produced fluids.

\section{Results and Discussion}

\subsection{Characterization of Asphaltenes}

\subsubsection{Thermogravimetric Analysis}

First, the Asf12 sample was subjected to thermogravimetric analysis using a constant heating ramp of $5 \mathrm{~K} / \mathrm{min}$ from 298 to $1073 \mathrm{~K}$ for selecting oxidation temperatures at which the asphaltene degradation was not too severe. As expected, the temperature at which there is a greater asphaltene decomposition under both oxidative and inert atmospheres is around $740 \mathrm{~K}$ which agrees with results obtained in previous studies [38-40]. Below $573 \mathrm{~K}$, there is no significant mass loss for both evaluated atmospheres. Hence, temperatures of 373 and 473 were selected for asphaltene thermal treatment under isothermal conditions. Curves of mass loss and the rate of mass loss of Asf12 under dry air and $\mathrm{N}_{2}$ injection can be found in Figure $\mathrm{S} 1$ of the Supporting Information.

There are two steps related to the change of the asphaltene molecule at different times of exposure of 1,5 , and $10 \mathrm{~h}$ under isothermal conditions of $473 \mathrm{~K}$. First, asphaltene undergoes a small mass loss until the isothermal condition is reached, which could be due to humidity in the sample. Then, at the working temperature, the asphaltene mass increased possibly due to the oxygen incorporation in the asphaltene molecular structure, as well as polymerization and addition reactions during the oxidation process [41,42]. At $473 \mathrm{~K}$, chemical reactions between oxygen and asphaltene occur, altering and modifying the functional groups in the molecule. A higher increase of mass is produced at longer exposure time. The reaction of excess oxygen with asphaltenes could lead to the formation of different types of functional groups that would modify chemical and physical properties like solubility, affinity, polarity, aromaticity, among others [43]. Table 1 shows the asphaltene mass increase at $473 \mathrm{~K}$ for different exposure times of 1,5 and $10 \mathrm{~h}$ under an oxidizing atmosphere with a constant air flow of $100 \mathrm{~mL} / \mathrm{min}$. The highest mass increase was observed after $10 \mathrm{~h}$ compared to those obtained at 1 and $5 \mathrm{~h}$, which indicates that by increasing the exposure time, the sample acquires more oxygen in its structure. It should be mentioned that mass changes are a balance between added oxygen and removal of alkyl substituent and heteroatoms such as nitrogen and sulfur. These results suggest that under these conditions these factors nearly compensate each other. For a treatment temperature of $373 \mathrm{~K}$, no significant mass gain under isothermal conditions was observed.

Table 1. Asphaltene mass increase at $473 \mathrm{~K}$ for different exposure times of 1,5 and $10 \mathrm{~h}$ under an oxidizing atmosphere with a constant air flow of $100 \mathrm{~mL} / \mathrm{min}$.

\begin{tabular}{cc}
\hline Exposure Time (h) & Mass Increase (\%) \\
\hline 1 & 0.20 \\
5 & 0.57 \\
10 & 2.70 \\
\hline
\end{tabular}

FTIR was coupled to the TGA to analyze the conversion of N to NOx as a function of time. Figure 1 shows the behavior of the NOx functional group for oxidation of Asf12 samples at $473 \mathrm{~K}$ and an exposure time of $5 \mathrm{~h}$. FTIR spectra were analyzed for 1550 and $1365 \mathrm{~cm}^{-1}$ bands related to asymmetric vibrations and symmetrical vibrations of nitroalkanes, respectively. Results show that after the first hour of oxidation the NOx generation increases until $5 \mathrm{~h}$ where it reaches its maximum conversion. 


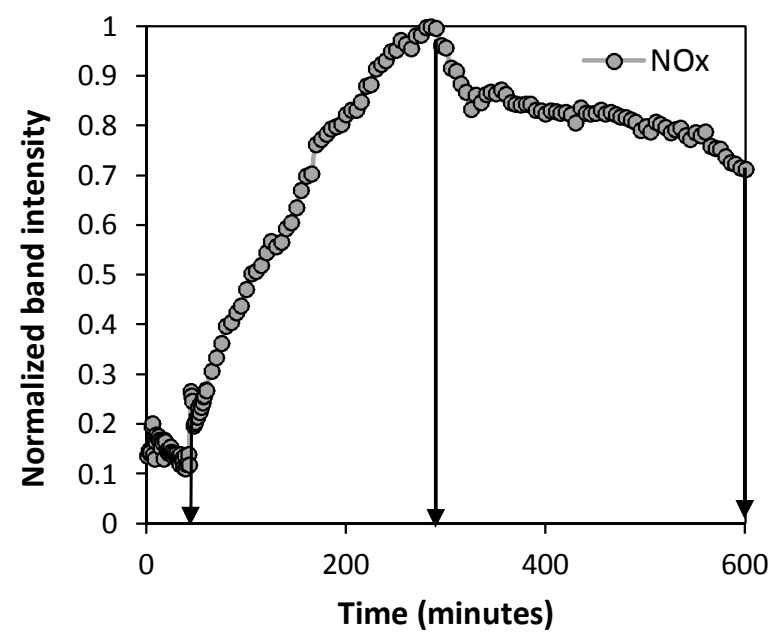

Figure 1. Generation of NOx groups during oxidation of asphaltenes as a function of exposure time and temperature of $473 \mathrm{~K}$.

\subsubsection{Elemental Analysis}

According to the TGA results, asphaltenes for emulsion preparation were thermally treated at 373 and $473 \mathrm{~K}$ under air injection using a muffle. Table 2 shows the elemental analysis $(\mathrm{C}, \mathrm{H}, \mathrm{N}, \mathrm{S}$, and $\mathrm{O})$ for each sample of asphaltenes before and after thermal treatment. Also, Figure 2 shows trends of the H/C ratio [44], and the degree of oxidation and reactivity of the carbon according to the $\mathrm{O} / \mathrm{C}$ parameter [45] for Asf12/473 as a function of exposure time. As expected, with the increase in oxidation temperature, percentages of $\mathrm{C}, \mathrm{H}$, and $\mathrm{N}$ decreases while the proportion of oxygen increases [32]. $\mathrm{S}$ changes were relatively low. Hosseinpour et al. $[46,47]$, showed that asphaltenes interact with oxygen through different reactions depending on the oxidation temperature. They found that at temperatures below $533 \mathrm{~K}$, oxidation is dominant when oxygen is chemisorbed at the exposed active sites of asphaltenes as carbons and heteroatoms and that the H/C ratio of asphaltenes also decreases because the aliphatic chains of the asphaltenes are oxidized to form compounds during oxidation at low temperature.

The reduction in the $\mathrm{H} / \mathrm{C}$ ratio indicates removal of aliphatic chains as well as aromaticity (ratio between the aromatic and aliphatic moieties) increasing. This result is due to the reduction in aliphatic chains regarding the number of aromatic rings in the asphaltene molecular structure [44]. For instance, oxidation of branched aliphatic chains to ketones could result in the simultaneous removal of aliphatic moieties. Conversely, the increase in the $\mathrm{O} / \mathrm{C}$ ratio indicates that there is a significant reactivity in the asphaltenes [48]; both trends are observed for the samples that are subjected to a higher temperature and a longer time of exposure. Also, an increase of $\mathrm{O} / \mathrm{C}$ could also be due to carbon reduced with side chain cleavage during $\mathrm{N}$ and $\mathrm{S}$ oxidation.

Table 2. Elemental Analysis of untreated and thermally treated asphaltene samples under an air atmosphere at different temperatures of 373 and 473, and different exposure times of 1, 5, and $10 \mathrm{~h}$.

\begin{tabular}{|c|c|c|c|c|c|c|c|c|c|c|}
\hline \multirow{2}{*}{ Sample } & \multirow{2}{*}{$\begin{array}{l}\text { Exposure } \\
\text { Time (h) }\end{array}$} & \multicolumn{9}{|c|}{ Parameter } \\
\hline & & $C(w t \%)$ & H (wt \%) & N (wt \%) & $S(w t \%)$ & $O *(w t \%)$ & $\mathrm{H} / \mathrm{C}$ & $\mathrm{O} / \mathrm{C}$ & N/C & $\mathrm{S} / \mathrm{C}$ \\
\hline Asf12 & - & 82.52 & 7.291 & 2.252 & 5.291 & 2.646 & 1.061 & 0.025 & 0.023 & 0.024 \\
\hline Asf12/373 & 5 & 80.11 & 7.154 & 1.941 & 5.113 & 5.682 & 1.056 & 0.054 & 0.020 & 0.024 \\
\hline \multirow{3}{*}{ Asf12/473 } & 1 & 77.83 & 6.038 & 1.932 & 4.956 & 9.244 & 0.931 & 0.082 & 0.021 & 0.024 \\
\hline & 5 & 75.42 & 5.221 & 0.685 & 4.813 & 13.861 & 0.831 & 0.138 & 0.008 & 0.024 \\
\hline & 10 & 72.17 & 4.816 & 0.618 & 4.219 & 18.177 & 0.801 & 0.190 & 0.007 & 0.022 \\
\hline
\end{tabular}

* by difference. 


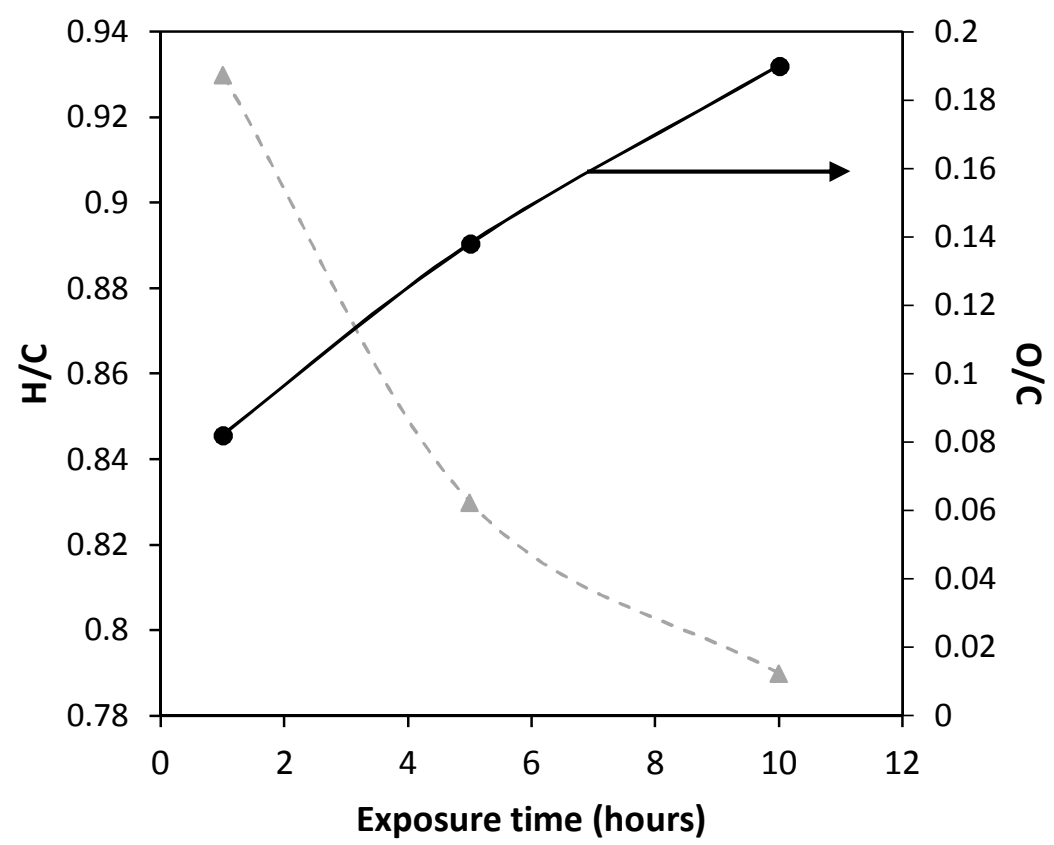

Figure 2. Effect of exposure time on $\mathrm{H} / \mathrm{C}$ and $\mathrm{O} / \mathrm{C}$ parameters for Asf12/473 sample after air injection at under isothermal conditions of $473 \mathrm{~K}$ for 1,5 , and $10 \mathrm{~h}$.

Removal of aliphatic chains, concerted with oxygen acquisition, is consistent with the small changes in mass experimented by sulfur (see Table 2). In the reaction in Figure 3, simple molecular models are used to illustrate some plausible hypothetical oxidation changes suggested by the elemental analysis and FTIR. First is the oxidation of aliphatic chains which is expected to occur to aromatic rings to afford nitrogen elimination for NOx generation, ring contraction, and ketone formation. Oxidation to ketones and sulphoxides is consistent with FTIR results, whereas nitrogen elimination is consistent with the increase in the production of the NOx group. As suggested by the reaction model, oxidation of sulfide to sulfoxide is an attractivepossibility. Here (Figure 3) the exciting removal of both nitrogen and alkyl chains, as well as the incorporation of oxygen are underlined.

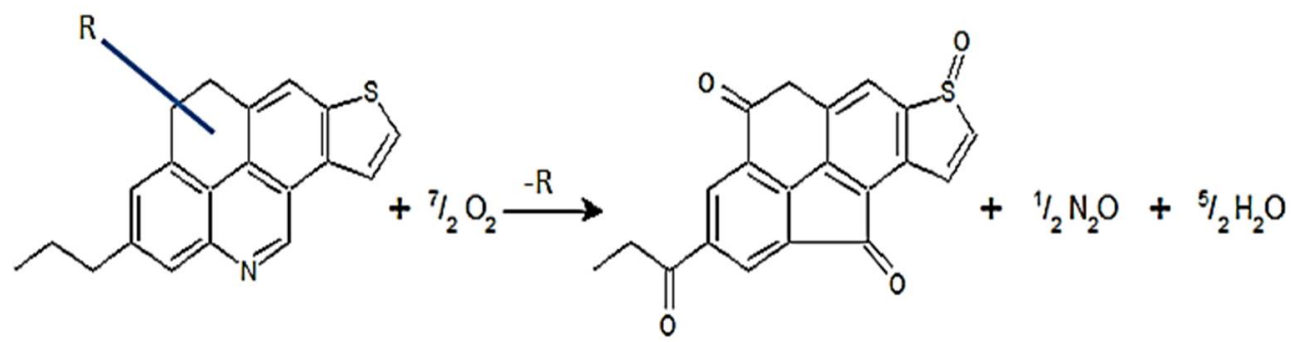

Figure 3. The hypothetical oxidation reaction of asphaltenes illustrating the expected chemical changes in functional groups: Oxidation to ketones and sulphoxide, and nitrogen and alkyl chain removal.

\subsubsection{Solubility of Thermally Modified Asphaltene}

Each asphaltene sample was dissolved in toluene at different concentrations starting from a 50,000 $\mathrm{mg} / \mathrm{L}$ base solution $[49,50]$. Table 3 shows the solubility of the asphaltenes samples as a function of the time of exposure to the oxidation, where changes in orders of magnitude were obtained depending on sample and exposure time. Although solubility depends on many factors, these results are coherent with the above elemental analysis interpretation (Table 2) regarding both alkyl removal and increase sample polarity after oxidation. 
Table 3. Asphaltenes solubility in toluene before and after oxidation at 373 and $473 \mathrm{~K}$. Solubility tests are conducted at $298 \mathrm{~K}$.

\begin{tabular}{ccc}
\hline Sample & Exposure Time (h) & Concentration (mg/L) \\
\hline Asf12 & - & 20,000 \\
\hline Asf12/373 & 5 & 15,000 \\
\hline \multirow{2}{*}{ Asf12/473 } & 1 & 2500 \\
& 5 & 2100 \\
& 10 & 1500 \\
\hline
\end{tabular}

\subsubsection{FTIR Analysis of Solid Asphaltenes}

The FTIR spectra were used to the calculate of percentage indexes of aromatic, aliphatic, carbonyl groups and sulphoxides, among others (see Table S1 in the Supporting Information) [51]. For all samples, two regions were analyzed in the corresponding spectra. These regions were related to aromatic (700-900 $\mathrm{cm}^{-1}$ and $\left.1400-1600 \mathrm{~cm}^{-1}\right)$ and aliphatic $\left(2700-3000 \mathrm{~cm}^{-1}\right)$ compounds and allow the calculation of various indexes in a comparable way of the different compositions of the fractions obtained. The results obtained by FTIR can be related to previous ${ }^{13} \mathrm{C}$ - and ${ }^{1} \mathrm{H}-\mathrm{NMR}$ analysis studies whereby integration of characteristic bands of aromatic and aliphatic regions also indicate changes in the aromatic carbons, and the number of carbons in the side chains of alkyl and aromatic rings [52,53]. The increase in oxidation time causes cracking and condensation reactions to be experienced which contribute to an increase in aromaticity while the aliphatic carbons decrease along with the hydrogen content $[54,55]$. Figure 4 shows the FTIR spectra of the Asf12 for (a) different treatment temperatures and a fixed exposure time of $5 \mathrm{~h}$ and (b) different exposure times for a fixed treatment temperature of $473 \mathrm{~K}$. For the treated samples, the bands of each spectrum have an increasing transmittance after oxidation, indicating that there are changes in the structure of the asphaltene molecule as well as the increasing aromaticity because aromatic rings are more exposed and the aliphatic chains that surround are less $[54,56]$. These increases are represented in the increase of the peaks between $700-900 \mathrm{~cm}^{-1}(\mathrm{CH}$ aromatic), $1400-1600 \mathrm{~cm}^{-1}$ (C-C aromatic), $1700-1725 \mathrm{~cm}^{-1}$ (O-H groups) and $2700-3000 \mathrm{~cm}^{-1}$ (alkanes and aliphatic structures). Comparing the intensity of the strong band near 2900 and band $1700 \mathrm{~cm}^{-1}$, a decrease in the aliphatic chains/ketone ratio is observed. Also, the sulfoxide group has a band in the $1030-1060 \mathrm{~cm}^{-1}$ range which there is evidence in this spectrum and others. However, the band is weak and also appears in the untreated asphaltene. It can be observed from Figure $4 \mathrm{~b}$ that a higher transmittance band is obtained for higher exposure time in the ranges $675-900 \mathrm{~cm}^{-1}$ corresponding to aromatic structures (C-O), $1365-1725 \mathrm{~cm}^{-1}$ corresponding to aromatic and aliphatic structures $(\mathrm{C}-\mathrm{H}, \mathrm{C}-\mathrm{C}$, and $\mathrm{C}=\mathrm{O}), 1715 \mathrm{~cm}^{-1}$ band corresponding to the ketone group, and $2800-2900 \mathrm{~cm}^{-1}$ corresponding to aldehyde groups ( $\mathrm{RR}^{\prime} \mathrm{C}=\mathrm{O}$ and $\mathrm{C}-\mathrm{H}$ ) [33]. After oxidation at 1 and $5 \mathrm{~h}$ similar results are observed, but after $10 \mathrm{~h}$ an increase in the transmittance of approximately $10 \%$ is obtained.

The FTIR spectra of each of the asphaltenes samples were used to calculate the structural properties (see Table S1 in the Supporting Information) where each index is a function of different spectral bands. The bands associated with aromatic components are $3050 \mathrm{~cm}^{-1}(\vee \mathrm{C}-\mathrm{H})$ and aromatic systems $1600 \mathrm{~cm}^{-1}$ ( $v$ C=C y C-H) [57-59]. Also, bands for aliphatic components 720, 1460, 1350, 2872, 2962, 2953 and $2926 \mathrm{~cm}^{-1}$ (groups $\vee \mathrm{C}-\mathrm{H}, \mathrm{CH}_{2}$, and $\mathrm{CH}_{3}$ ). The structural and functional indexes were calculated based on the band's area, which was determined by FTIR spectra deconvolution [60]. Indexes were used to determine the structural behavior and to relate the chemical compositions of each of the asphaltenes samples when subjected to various oxidation temperatures. The qualitative compositional indexes of the asphaltenes samples are presented as a function of oxidation temperature and exposure time in Figures S2 and S3 in the Supporting Information, respectively. It can be observed from Figures S2 and S3 that the indexes may vary depending on the resolution and transmittance of the selected areas corresponding to each wavelength of each compound. There are structural changes in the asphaltenes by oxidation processes, mainly acquiring greater aromaticity due to the increase in the $\mathrm{C}_{\mathrm{ar}} / \mathrm{H}_{\mathrm{ar}}$ ratio and branching 
of the aliphatic chains, where the aromatic rings increase regarding the aromatic hydrogens and is in agreement with chemical analyses results. On the other hand, aliphatic groups, sulfoxides and the length of aliphatic chains tend to be reduced when increasing the oxidation temperatures [61,62]. Also, it is observed that there is an increase of the ketone group and the reduction of sulfoxides with oxidation.

(a)

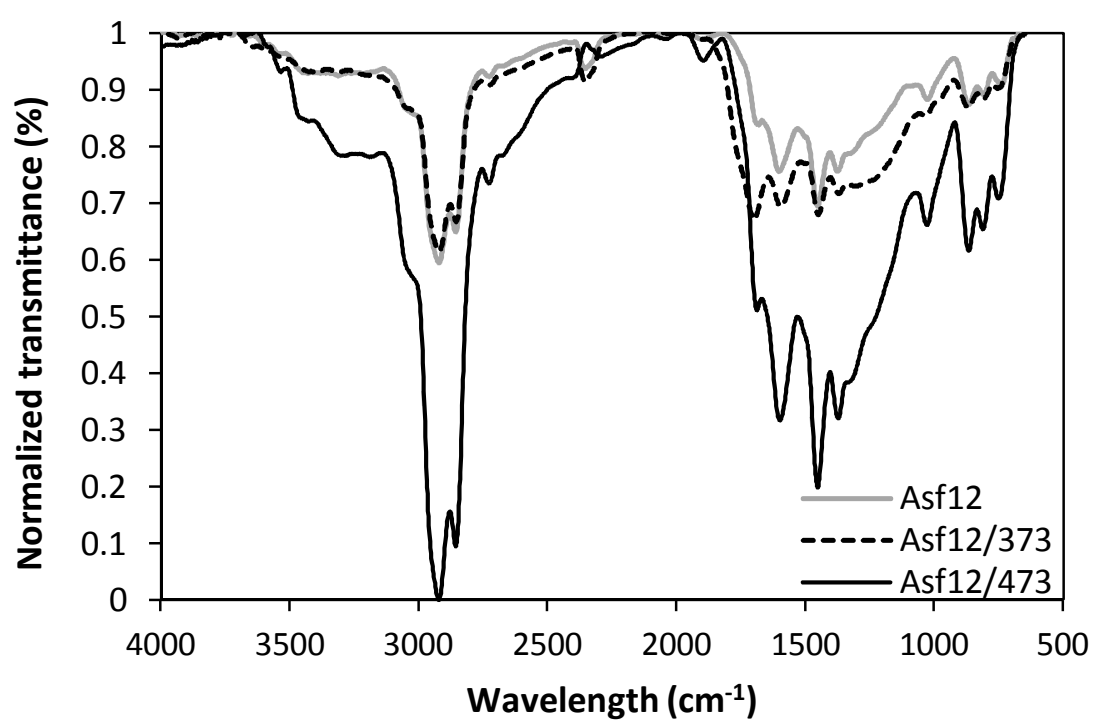

(b)

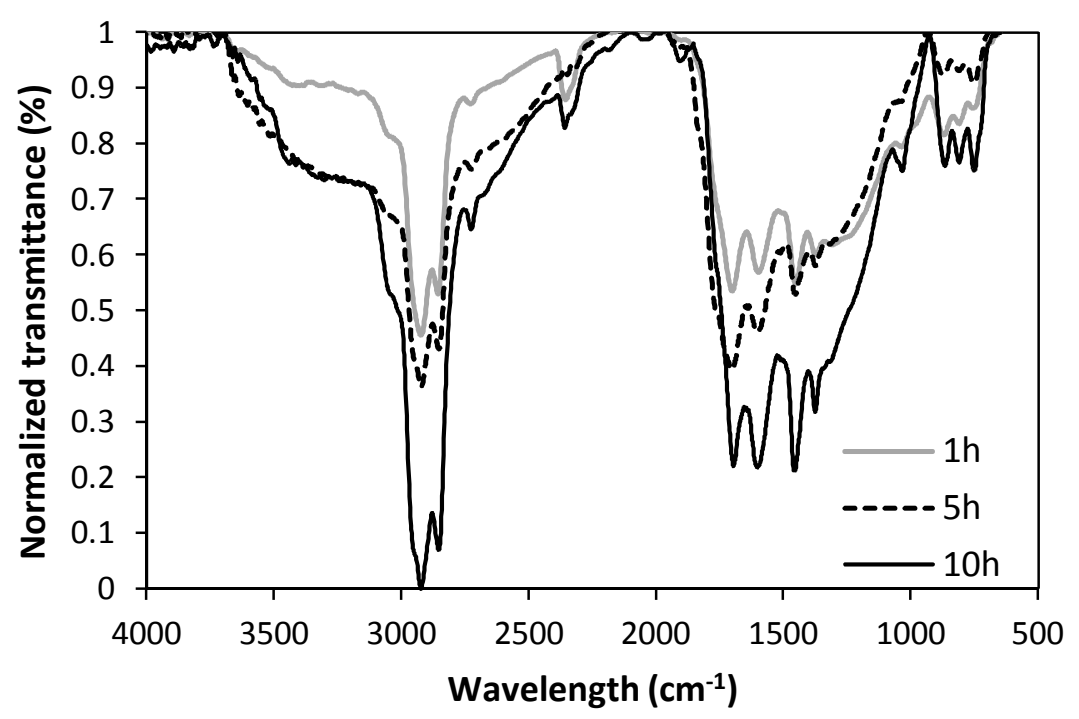

Figure 4. FTIR spectra of the Asf12 sample submitted to air flow for (a) different temperatures of 373 and $473 \mathrm{~K}$ for a fixed exposure time of $5 \mathrm{~h}$, and (b) different exposure times of 1,5 , and $10 \mathrm{~h}$ at a fixed temperature of $473 \mathrm{~K}$.

\subsection{Emulsions}

Emulsions were prepared with three model solutions with different water-toluene ratios and variable concentrations of asphaltenes. Emulsions were characterized by average droplet diameter, phase volume, and surface and interfacial tension.

\subsubsection{Oxidation Temperature Effect}

The effect of the oxidation temperature on the formation of $\mathrm{W} / \mathrm{O}$ emulsions of the treated asphaltenes at 373 and $473 \mathrm{~K}$ for a model solution to water ratio of 1:1 and different asphaltene concentrations of 100, 500, and $1000 \mathrm{mg} / \mathrm{L}$ is shown in Figure 5 and summarized in Table 4. It is observed that for the 
untreated asphaltenes and the asphaltenes oxidized at 373 and $473 \mathrm{~K}$, the amount of W/O emulsion formed increases as the asphaltene concentration increases, i.e., increase in concentration increases the quantity of oil-soluble natural surfactants (NS) leading to a higher percentage of W/O phase. Moreover, oxidation increases water affinity and reduce oil solubility thus promoting NS adsorption at the interface [23,29]. This effect can be explained due to as the relative coverage of asphaltene at the model solution-water interface increases, the interfacial film may behave more elastic than viscous which increases the system stiffness that has been attributed to asphaltenes cross-linking $[19,63]$. The emulsification mechanism is regulated by the soluble asphaltenes that diffuse in the oil and reach the water-oil interface where they tend to adsorb by reducing the interfacial tension. Once adsorbed in the water-oil interface, the asphaltenes undergo a reorganization that leads to the formation of a rigid and stable elastic interfacial film [64-66]. This adsorption at the oil-water interface reduces the net energy of the system and is strongly limited by the amount and composition of asphaltenes. On the other hand, asphaltenes have a greater tendency to adsorb at the oil-water interface and form a stronger interfacial film at their solubility limit. Consequently, the more polar and less soluble asphaltenes are those with a greater tendency to form stronger interfacial films [67-69]. Also, after the stirring procedure, the droplets will coalesce until the interfacial area is small enough for the asphaltenes present in the mixture to stabilize the interface. As the asphaltene concentration increases, the more interfacial area can be stabilized, and the drop size will be smaller. The oxidized asphaltenes stabilize the interface at lower concentrations suggesting that a larger proportion of these asphaltenes adsorb at the interface.

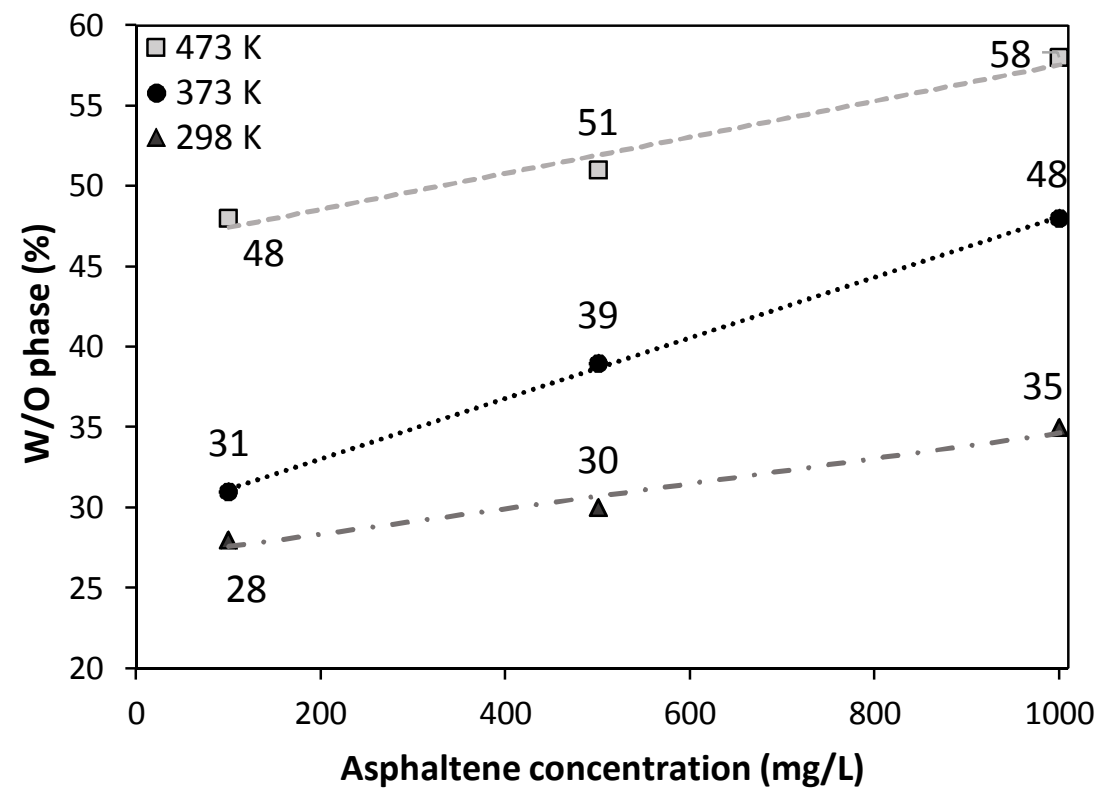

Figure 5. Formation of $\mathrm{W} / \mathrm{O}$ emulsions as a function of the asphaltenes concentration for the different oxidation temperatures, oxidation time of $5 \mathrm{~h}$, and a model solution to water ratio of 1:1.

Table 4. Phase percentage of $\mathrm{W} / \mathrm{O}$ and $\mathrm{O} / \mathrm{W}$ emulsions for different asphaltene concentrations of 100, 500 , and $1000 \mathrm{mg} / \mathrm{L}$, oxidation time of $5 \mathrm{~h}$, and a model solution to water ratio of 1:1 using Asf12, Asf12/473 and Asf12/473.

\begin{tabular}{ccccccc}
\hline \multirow{2}{*}{ Concentration (mg/L) } & \multicolumn{3}{c}{ W/O Emulsion (\%) } & \multicolumn{3}{c}{ O/W Emulsion (\%) } \\
\cline { 2 - 7 } & Asf12 & Asf12/373 & Asf12/473 & Asf12 & Asf12/373 & Asf12/473 \\
\hline 100 & 28 & 31 & 48 & 52 & 25 & 3 \\
500 & 30 & 39 & 51 & 70 & 61 & 3 \\
1000 & 35 & 48 & 58 & 65 & 52 & 2 \\
\hline
\end{tabular}


Also, when comparing the amount of W/O phase formed for a fixed asphaltene concentration, it is observed that samples exposed to higher temperatures are more prone to contribute to the formation of W/O emulsions (Table 4). For a fixed asphaltene concentration of $500 \mathrm{mg} / \mathrm{L}$, the amount of W/O phase is 30, 39, and 51 for the Asf12, Asf12/373, and Asf12/473 samples, respectively, indicating that when asphaltenes are oxidized at 373 and $473 \mathrm{~K}$ for the same exposure time, the formation of W/O emulsions increases by approximately $30 \%$ and $70 \%$ under the evaluated conditions. Similarly, for fixed concentrations of 100 and $1000 \mathrm{mg} / \mathrm{L}$, the formation of W/O emulsions shows an increase of $7 \%$ and $25 \%$, and $37 \%$ and $66 \%$ for asphaltenes treatment temperatures of 373 and $473 \mathrm{~K}$. These results indicate that as the asphaltenes concentration increased, the suitability of W/O phase formation increases. As the aromaticity increases, the decrease of side alkyl chains and the reduction of the alkyl chains ramification of the asphaltenes molecule can be responsible for the emulsions stabilization [33]. Also, the decreased solvency of treated samples, which decreases as treatment temperature increases, may lead to a higher preference of asphaltenes for being at the model solution-water interface than in bulk [25].

The formation of $\mathrm{O} / \mathrm{W}$ emulsions was also evaluated (Table 4). Adsorbed asphaltenes at oil/water interface contribute to steric repulsion between oil droplets, inhibiting the drop coalescence and stabilizing $\mathrm{O} / \mathrm{W}$ emulsion. Shi et al. [70], demonstrated that adsorbed asphaltenes at oil/water interface could enhance the surface potential of the oil droplets. The change of the surface potential of oil droplets with asphaltene concentration is most likely due to a change of the adsorbed amount of asphaltenes and their adsorption state at the oil/water interface, as also indicated by the change of the oil/water interfacial tension with increasing the asphaltene concentration in toluene. In addition, asphaltenes significantly strengthens the repulsion between the oil droplets, preventing the drop coalescence and enhancing the emulsion stability. Also, Andrews et al. [71], analyzed Langmuir-Blodgett films of asphaltenes and related model compounds with sum frequency generation (SFG) vibrational spectroscopy to determine the orientation of different funtional groups at the oil-water interfase. Results shows that asphaltenes core adopt an orientation in parallel to the interface and the alkyl chains perpendicular to the interface. In addition, functional O-containing groups either on the alkyl chains or at the edges of the core play a fundamental role in molecular orientation. As explained by Yarranton [72], for $\mathrm{O} / \mathrm{W}$ emulsion the electrostatic forces arise from a balance of the ionic charges on the surface of the oil drops that can be destabilized when in the adsorbed or diffused phase a surfactant such as asphaltenes is found, contributing to a greater repulsion between the drops. For the W/O emulsion, a physical barrier is created between the drops created by the adsorption of the asphaltenes at the interface, increasing the steric forces due to work required to move these asphaltenes from that interface [72]. For the Asf12 sample, it was observed that for an asphaltene concentration of $100 \mathrm{mg} / \mathrm{L}$, a $52 \%$ of the sample was observed to be an $\mathrm{O} / \mathrm{W}$ emulsion, indicating a $20 \%$ of non-emulsified water in the sample. Meanwhile, for concentrations of 500 and $1000 \mathrm{mg} / \mathrm{L}$, the formation of $\mathrm{O} / \mathrm{W}$ emulsions corresponds to $70 \%$ and $65 \%$ of the sample, indicating that by increasing the asphaltenes concentration, is in either $\mathrm{W} / \mathrm{O}$ or $\mathrm{O} / \mathrm{W}$ phase. For the oxidized samples, the formation of $\mathrm{O} / \mathrm{W}$ emulsions was lower than for the Asf12 sample. For a treatment temperature of $373 \mathrm{~K}$, the percentage of $\mathrm{O} / \mathrm{W}$ emulsion observed was $25 \%, 61 \%$ and $52 \%$ for asphaltenes concentrations of 100,500 and $1000 \mathrm{mg} / \mathrm{L}$, respectively. A $44 \%$ of non-emulsified water was obtained for $100 \mathrm{mg} / \mathrm{L}$, and for concentrations of 500 and $1000 \mathrm{mg} / \mathrm{L}$, all water was in the emulsion phases. It means that for both concentrations of 500 and $1000 \mathrm{mg} / \mathrm{L}$ there are only two phases corresponding to W/O and $\mathrm{O} / \mathrm{W}$ emulsions. Hence, a higher amount of $\mathrm{O} / \mathrm{W}$ emulsion in $500 \mathrm{mg} / \mathrm{L}$ system is a consequence of the lower amount of W/O phase. In the case of the Asf12/473 sample, little O/W formation was observed with percentages of $3 \pm 1 \%$ for all asphaltenes concentrations evaluated, indicating that the inclusion of the oxygen to the asphaltenes molecule inhibits the stabilization of the water-model solution interfacial film when water is the continuous phase. The smaller drop sizes with increased oxidation temperature suggest that the oxidation reactions are created an increased amount of surface active species, and an increase in the amount of stabilizer will also lead to smaller droplets. 
Panels a to $\mathrm{c}$ in Figure 6 show the mean droplet diameter of the observed W/O and O/W emulsions as a function of the asphaltenes concentration for the different oxidation temperatures $(5 \mathrm{~h})$ and a model solution to water ratio of 1:1 for: (a) Asf12, (b) Asf12/373 and, (c) Asf12/473 samples. It is observed that for the Asf12, Asf12/373 and Asf12/473 samples, the main droplet diameter was always larger for the $\mathrm{W} / \mathrm{O}$ system than for the $\mathrm{O} / \mathrm{W}$ one. It is worth to mention that, in general, the dispersed phase droplets have a compact distribution for the $\mathrm{O} / \mathrm{W}$ emulsion, with drops of large sizes that occupy most of the volume of the $\mathrm{O} / \mathrm{W}$ phase, i.e., packing or distribution of the drops in the whole phase is compact. For the W/O emulsion, dispersed, relatively small, and homogenous drops can be found. For the $\mathrm{O} / \mathrm{W}$ emulsions, the average droplet diameter ranged from 13 to $86 \mu \mathrm{m}$, while for the W/O systems ranged from 3 to $9 \mu \mathrm{m}$. This result could be due to the increase in the polar group concentration at the interface leads to the reduction of interfacial tension and the formation of $\mathrm{W} / \mathrm{O}$ emulsions [73,74].

The results are consistent with a higher concentration of NS at the interface in W/O emulsion compared to $\mathrm{O} / \mathrm{W}$ emulsion. When compared to $\mathrm{W} / \mathrm{O}, \mathrm{O} / \mathrm{W}$ emulsions are quite sensitive to concentration changes suggesting that for this case interfaces are far from saturation at 100 and $500 \mathrm{mg} / \mathrm{L}$. Oxidation tends to produce smaller drop diameters indicating more stable emulsions. When comparing the droplet diameter for the three different samples Asf12, Asf12/373 and Asf12/473 at a fixed asphaltene concentration, it can be observed that lower sizes are obtained as the temperature of asphaltene oxidation increases. For a fixed concentration of $500 \mathrm{mg} / \mathrm{L}$, the mean droplet diameters in the W/O emulsions are 5.4, 4.6 and $3.9 \mu \mathrm{m}$ for Asf12, Asf12/373 and Asf12/473 samples, respectively, indicating a reduction of $15 \%$ and $28 \%$ that directly affects the stability of the samples and is in agreement with the results in Figure 6.
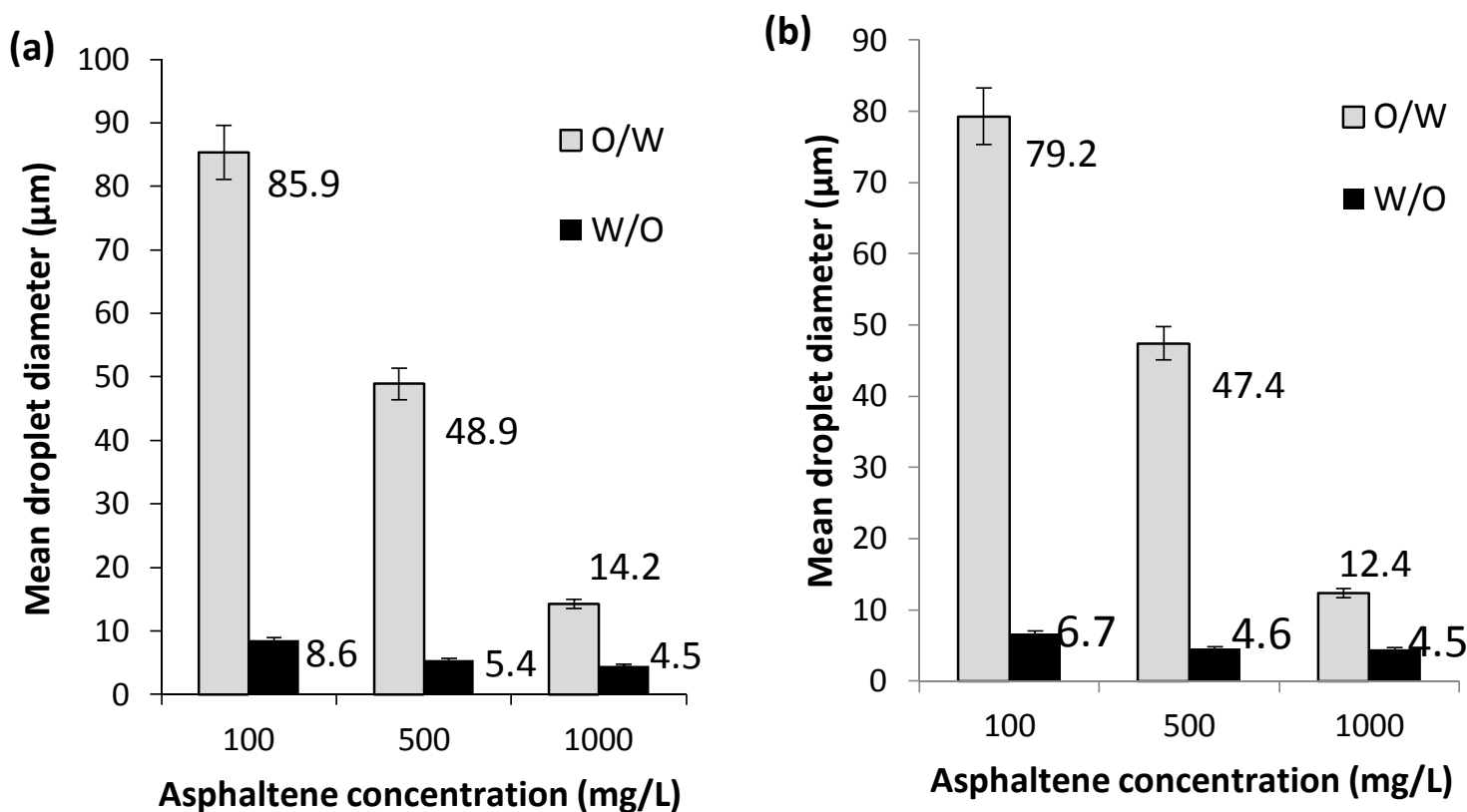

Figure 6. Cont. 


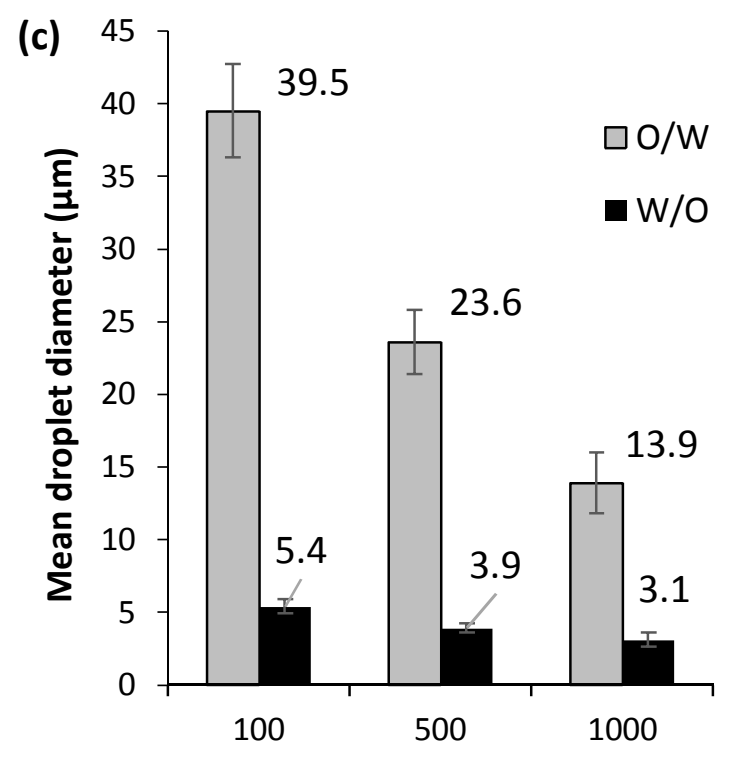

Asphaltene concentration (mg/L)

Figure 6. Mean droplet diameter of $\mathrm{W} / \mathrm{O}$ and $\mathrm{O} / \mathrm{W}$ emulsions for different asphaltene concentrations of 100,500 , and $1000 \mathrm{mg} / \mathrm{L}$, oxidation time of $5 \mathrm{~h}$ and a model solution to water ratio of 1:1 for (a) Asf12; (b) Asf12/373 and; (c) Asf12/473 samples.

\subsubsection{Effect of Model Solution to Water Ratio}

The effect of thermally treated asphaltenes in the formation of $\mathrm{W} / \mathrm{O}$ emulsions was evaluated for a model solution to water ratio of 1:4 and 4:1. The Asf12/473 sample was selected for the evaluation of the effect of the model solution to water ratio due to its low solubility. Figure 7 shows the (a) and (c) the phase percentage and in (b) and (d) the mean droplet diameter for systems using Asf12 and Asf12/473 (5 h) and for a model solution to water ratio of 4:1, respectively. It can be observed from Figure 7 that for Asf12 sample no W/O emulsion is formed for concentrations of asphaltenes of 100 and $500 \mathrm{mg} / \mathrm{L}$. However, a 76\% of W/O emulsion is obtained when the concentration is increased to $1000 \mathrm{mg} / \mathrm{L}$ when asphaltenes are oxidized at $473 \mathrm{~K}$, the emulsification process is enhanced regarding untreated asphaltenes, obtaining percentages of W/O phase of $74 \pm 1 \%$ for Asf $12 / 473$ concentrations of 100 and $500 \mathrm{mg} / \mathrm{L}$, and of $85 \%$ for $1000 \mathrm{mg} / \mathrm{L}$. Also, it is observed that the feasibility of $\mathrm{O} / \mathrm{W}$ formation decreased for the oxidized sample in comparison with the untreated one, as non-emulsified water was observed in the samples with 100 and $500 \mathrm{mg} / \mathrm{L}$ of asphaltene, corroborating the preference for stabilizing $\mathrm{W} / \mathrm{O}$ emulsions instead of $\mathrm{O} / \mathrm{W}$ due to reduction in the length of side alkyl chains and the branching in the aliphatic chains $[75,76]$. Also, when comparing the mean droplet diameter for W/O emulsions prepared with Asf12 and Asf12/473 samples, a decrease is observed, corroborating that by oxidizing the asphaltene molecule, more stable emulsions are obtained. Results suggest low emulsion formation for both analyzed asphaltene samples. For Asf12 no significant W/O emulsion formation is apparent at asphaltene concentrations below $1000 \mathrm{mg} / \mathrm{L}$.

In the case of a model solution to water ratio of 1:4 no significant changes in the emulsification behavior were observed. For both Asf12 and Asf12/473 samples and the three asphaltene concentrations evaluated of 100,500 , and $1000 \mathrm{mg} / \mathrm{L}$, a percentage of W/O emulsion of $20 \pm 1 \%$ was obtained. Nevertheless, the mean water droplet diameter decreased between $25 \%$ and $36 \%$ when using Asf12/473 samples. Conversely, $\mathrm{O} / \mathrm{W}$ emulsions were found to be less than $3 \%$ of the system, and the remaining amount of water was free of emulsions. 
(a)

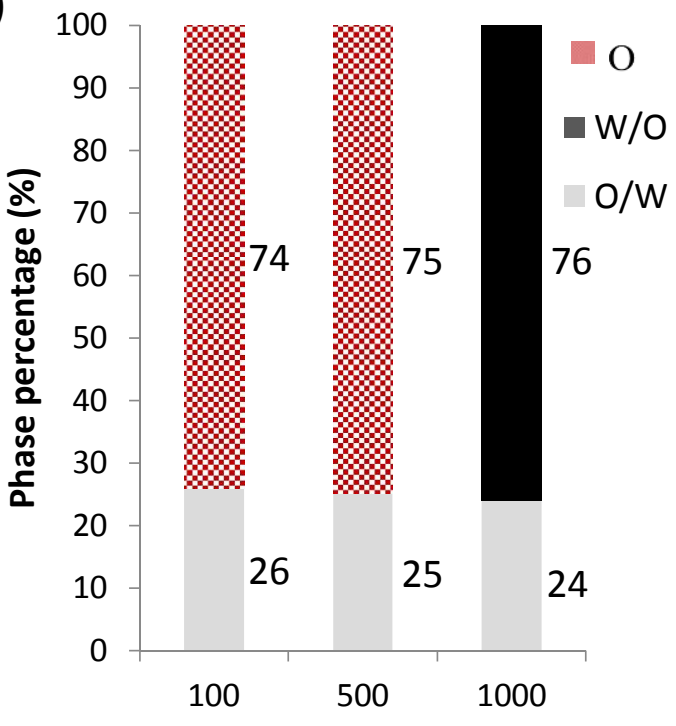

Asphaltene concentration $(\mathrm{mg} / \mathrm{L})$

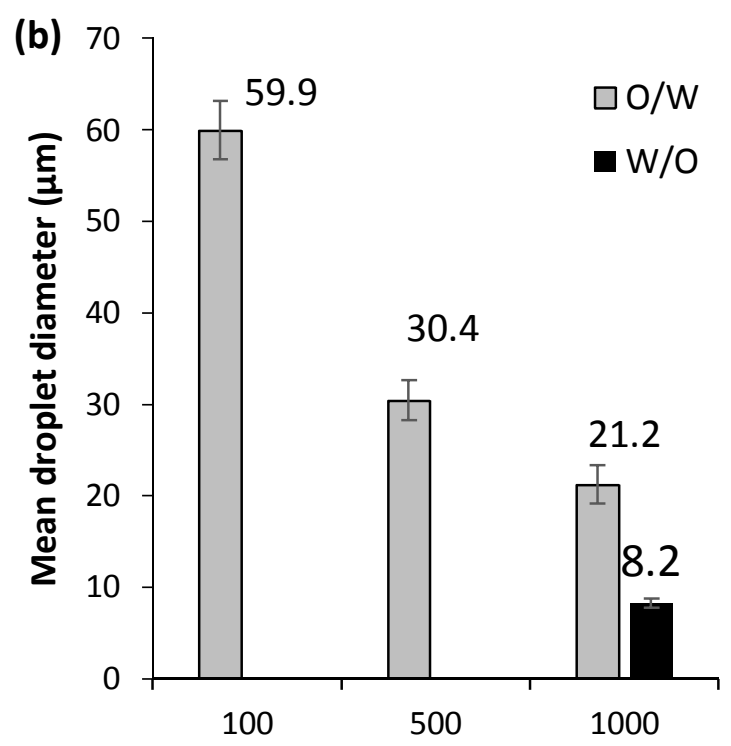

Asphaltene concentration ( $\mathrm{mg} / \mathrm{L})$ (c)

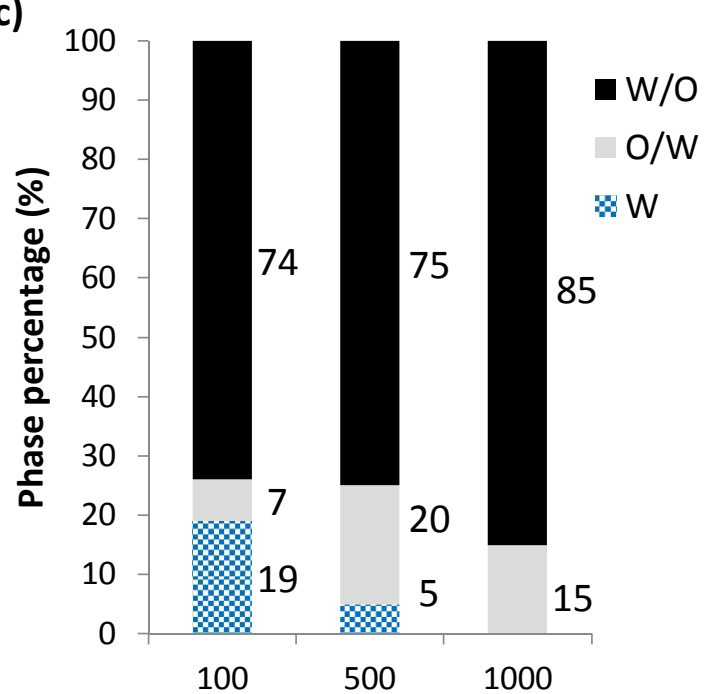

Asphaltene concentration (mg/L) (d)
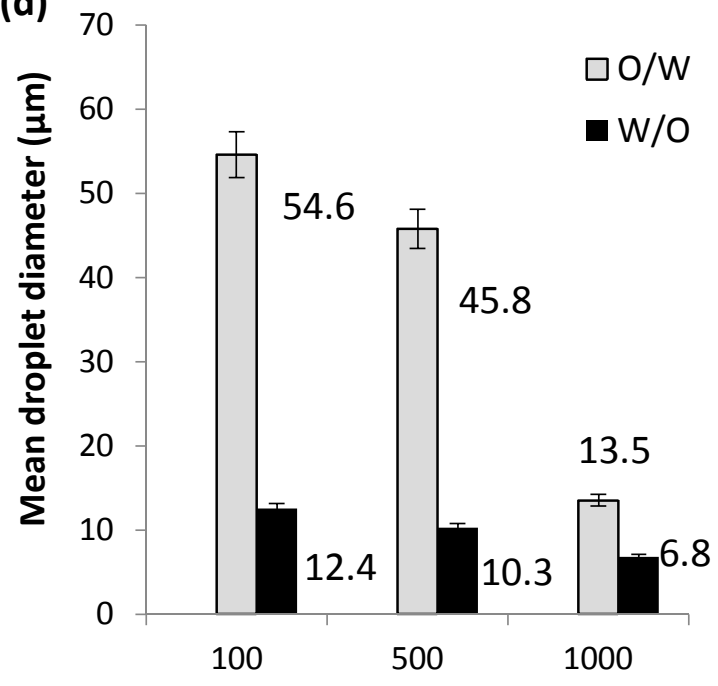

Asphaltene concentration (mg/L)

Figure 7. Phase percentage and mean droplet diameter of $\mathrm{W} / \mathrm{O}$ and $\mathrm{O} / \mathrm{W}$ emulsions for different asphaltene concentrations of 100,500 , and $1000 \mathrm{mg} / \mathrm{L}$, oxidation time of $5 \mathrm{~h}$, and a model solution to water ratio of 4:1 using (a,b) Asf12 and (c,d) Asf12/473.

\subsubsection{Effect of Exposure Time on Oxidative Atmosphere}

Asf12 were selected for the evaluation of the effect of exposure time to oxidation. Different exposure times of 1,5, and $10 \mathrm{~h}$ at $473 \mathrm{~K}$ were evaluated, and emulsions were prepared using a 1:1 model solution to water ratio and $1000 \mathrm{mg} / \mathrm{L}$ of asphaltenes samples. Results of the effect of the exposure time in the formation of W/O emulsions are presented in Figure 8 for: $(\mathrm{a}, \mathrm{c})$ phase percentage and $(b, d)$ mean droplet diameter. As it can be observed from Figure 8, by increasing the exposure time of asphaltenes to oxidation, there is a higher feasibility of $\mathrm{W} / \mathrm{O}$ emulsions formation as well as higher stability. This could be due to the increase aromaticity, and higher amount of ketone groups that are included as the oxygen adds to the asphaltene molecules, giving more rigidity to the viscoelastic film and hence, higher stability [31,77]. Also, a $40 \%$ of non-emulsified water was observed. After $5 \mathrm{~h}$ 
of exposure time, asphaltenes show a trend in reducing the amount of $\mathrm{O} / \mathrm{W}$ formed and could be mainly due to the reduction of $\mathrm{N}$-containing functional groups and is in agreement with the results of NOx production (Figure 1) where the oxidation of aliphatic chains occur to aromatic rings to afford nitrogen elimination for NOx generation, ring contraction, and ketone formation [78,79]. Also, as the $\mathrm{N}$ is mainly located in the asphaltenes' polyaromatic hydrocarbon (PAH) core [32], it can be inferred that the nitrogen substitution leads to a severe modification of the asphaltenes' PAH and hence, a change in the polarity of the molecule. Hence, according to the elemental analysis, the number of aromatic rings may be increased and lead to stabilization of the emulsions.

The mean droplet diameter decreased for all exposure times evaluated decreased regarding the untreated sample. As the exposure time increases the percentage of $\mathrm{W} / \mathrm{O}$ emulsion increases a result expected given higher polarity and lower oil solubility of Natural Surfactant (NS) stabilizing the W/O emulsion. Note that high percentages of water were obtained in all cases suggesting low stability of $\mathrm{O} / \mathrm{W}$ emulsions and hence high coalescence tendency. This result suggests that in this case reduction of drop diameter is not related to higher stability. It is reasonable to suggest that higher oxidation leads to increase in water solubility of NS responsible for the $\mathrm{O} / \mathrm{W}$ emulsions. In other words, their desorption from the interface is more likely leading to coalescence.

(a)

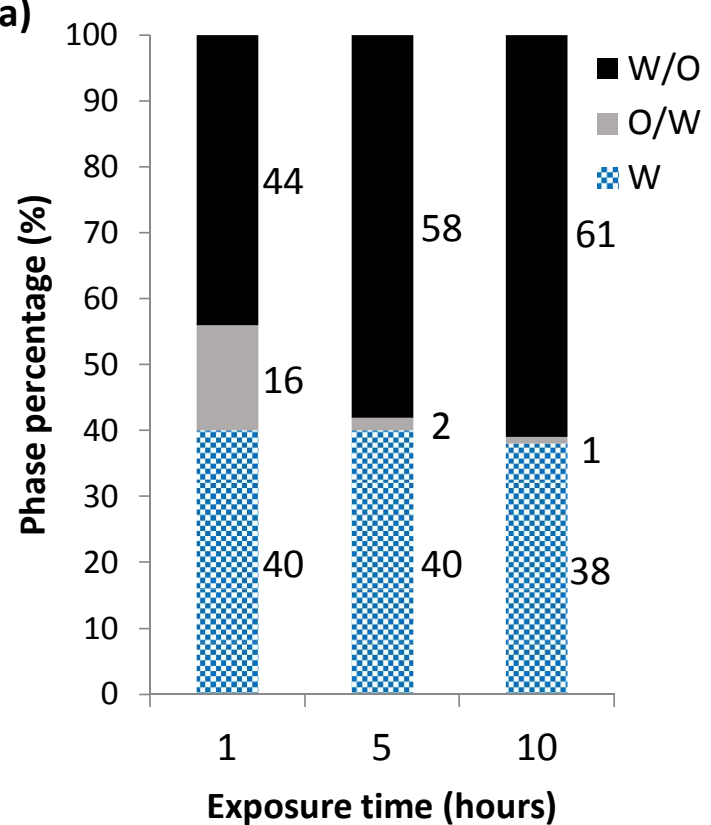

(b)

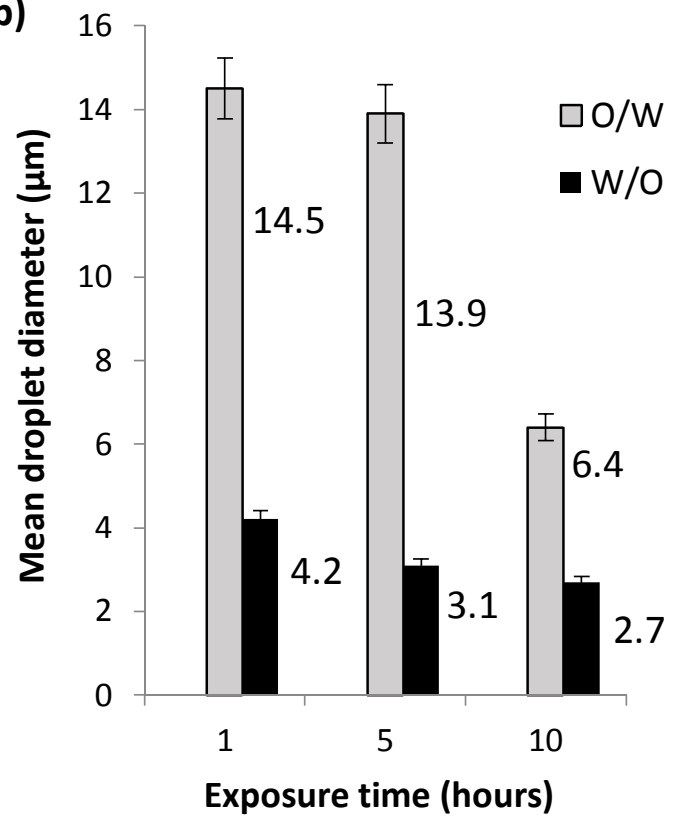

Figure 8. (a) Phase percentage and (b) mean droplet diameter of $\mathrm{W} / \mathrm{O}$ and $\mathrm{O} / \mathrm{W}$ emulsions for Asf12/473 samples with different exposure times to oxidation of 1, 5, and $10 \mathrm{~h}$. Experiments were conducted at a fixed Asf12/473 concentration of $1000 \mathrm{mg} / \mathrm{L}$ and a model solution to water ratio of 1:1.

\subsubsection{Interfacial Tension Measurements}

Interfacial tensions (IFT) were measured for emulsions with Asf12 and Asf12/473 K using neutral and alkaline water $(\mathrm{pH} \sim 12)$ to evaluate the presence of carboxylic acids on the formation of emulsions. It is expected that the IFT is reduced drastically by the presence of carboxylic acids in the oily medium. By ionization reactions, surface active compounds could be formed in the interfacial layer when contacting an alkaline aqueous solution [80]. Table 5 shows the results of IFT measurements for model solution-water systems at $298 \mathrm{~K}$. Model solutions were prepared with 100, 500, and $1000 \mathrm{mg} / \mathrm{L}$ of Asf12 and Asf12/473. The toluene-water and toluene-alkaline water IFT were $30 \pm 1 \mathrm{mN} / \mathrm{m}$ in both cases, which is in agreement with the results reported by Saien and Akbari [81]. 
For both Asf12 and Asf12/473 samples, the values of IFT decreased as the asphaltene concentration increased, corroborating that smaller droplets are because the IFT is reduced (see Figure 7). In the case of Asf12 model solutions at $1000 \mathrm{mg} / \mathrm{L}$, the values obtained of IFT were 22 and $9 \pm 1 \mathrm{mN} / \mathrm{m}$ for neutral and alkaline media, respectively. When the asphaltenes are submitted to the oxidation, the IFT slightly decreases to $19 \mathrm{mN} / \mathrm{m}$ in neutral water and remains constant in alkaline water, suggesting that the oxidation of asphaltenes under the conditions evaluated do not lead to the formation of additional carboxylic groups, and that emulsification mechanism can be more related to the presence of ketones [34], and the increase of the aromaticity in the asphaltenes samples. Hence, it can be said that when the molecular structure of asphaltenes is modified by the inclusion of oxygen, the stabilization of $\mathrm{O} / \mathrm{W}$ emulsions could be more related to specific asphaltenes-asphaltenes interactions which contribute to the strengthening of the interfacial film.

It should be mentioned that preliminary studies of interfacial tension, at the toluene-sample /aqueous sodium hydroxide interface, show no notable change when asphaltene solutions were compared with oxidized samples. This indicates that under the above conditions, no significant quantities of carboxylic acids were formed.

Table 5. Interfacial tensions for model solution-water systems at $298 \mathrm{~K}$. Model solutions were prepared with Asf12 and Asf12/473.

\begin{tabular}{cccc}
\hline Oily Medium & Aqueous Medium & Asphaltene Concentration $\mathbf{( m g} / \mathbf{L})$ & Interfacial Tension $\pm \mathbf{1} \mathbf{~ m N} / \mathbf{m}$ \\
\hline \multirow{3}{*}{ Asf12 model solution } & \multirow{2}{*}{ Water } & 100 & 28 \\
& & 500 & 26 \\
& Alkaline water & 1000 & 22 \\
\cline { 2 - 4 } & \multirow{3}{*}{ Wsf12/473 model solution } & 1000 & 9 \\
& & 100 & 25 \\
& & 500 & 23 \\
& Alkaline water & 1000 & 19 \\
\cline { 2 - 4 } & & 1000 & 10 \\
\hline
\end{tabular}

\section{Materials and Methods}

\subsection{Materials}

The asphaltenes were extracted with n-heptane (99\%, Sigma-Aldrich, St. Louis, MO, USA), from a Colombian heavy oil of $12{ }^{\circ} \mathrm{API}$ gravity, with asphaltene content of $18 \mathrm{wt} \%$. Toluene $(99.5 \%$, Merck KGaA, Darmstadt, Hesse, Germany) was used for solvency tests of thermally treated asphaltenes and the preparation of oil model solutions. Deionized water was employed for emulsions preparation ( $\mathrm{pH} ~ 7)$. Potassium Bromide (KBr, PIKE Technologies, Inc., Boston, MA, USA) was used for FTIR measurements. Dry air (Linde, Medellín, ANT., Colombia) was used for both asphaltenes oxidation in TGA and muffle. Nitrogen ( $\mathrm{N}_{2}$, Linde, Medellín, ANT., Colombia) was used for evaluation of mass changes in asphaltene by TGA.

\subsection{Asphaltene Isolation and Air Exposure}

The asphaltenes were isolated from the crude oil following a standard procedure [82,83]. First, an excess of $n$-heptane was added to the crude oil in a 40:1 ratio. The mixture is sonicated for $2 \mathrm{~h}$ at $298 \mathrm{~K}$ and then stirred at $300 \mathrm{rpm}$ for $20 \mathrm{~h}$. Then, the solution is centrifuged at $4500 \mathrm{rpm}$ for 30 min using a 306 Hermle Universal Centrifuge (Labnet International Inc., Edison, NJ, USA). The filtrate is washed several times with $n$-heptane until the effluent absorbance was the same than that of pure $n$-heptane. Absorbance measurements were performed with a GENESYS 10S UV-Vis spectrophotometer (Thermo Scientific, Waltham, MA, USA). Finally, the asphaltenes obtained are homogenized in a mortar. For emulsion preparation, the asphaltenes were thermally treated at 373 and $473 \mathrm{~K}$ using a muffle (Industrias Terrígeno, Medellín, ANT., Colombia) with a constant air flow of $100 \mathrm{~cm}^{3} / \mathrm{min}$ with heating ramps of $5 \mathrm{~K} / \mathrm{min}$ and different exposure times of 1,5 and $10 \mathrm{~h}$. 
Treatment temperatures were selected from thermogravimetric analyzer according to Section 2.1.1 above. Asphaltenes in this study are named according to the treatment temperature. For instance, asphaltenes extracted from the $12^{\circ}$ API gravity crude oil are named Asf12, and asphaltenes thermally treated under an air flow at 373 and $473 \mathrm{~K}$ are named Asf12/373 and Asf12/473, respectively.

\subsection{Asphaltene Characterization}

\subsubsection{Elemental Analyses}

Elemental analysis for each of the asphaltenes samples was performed by the ASTM D 5291 standard [84] using an elemental analyzer (Perkin-Elmer, Waltham, MA, USA), from which the percentage is determined by the weight of $\mathrm{C}, \mathrm{H}, \mathrm{N}$ and $\mathrm{S}$ for each sample. The oxygen in the samples was determined by difference.

\subsubsection{Solubility Tests}

The solubility tests were performed with toluene at room conditions for each asphaltene sample before and after thermal treatment. Toluene was selected according to its excellent solvency with asphaltenes due to its aromatic hydrocarbon nature [49,50]. For these tests, the initial asphaltenes concentration is fixed at $5 \mathrm{wt} \%$. For each case, the supernatant is removed after a process of stirring, sonication and centrifugation. Subsequently, the solvent is evaporated, and the obtained asphaltenes are dried and quantified. All the tests were performed at room temperature (298 K) and atmospheric pressure.

\subsubsection{Thermogravimetric Analysis}

Thermogravimetric analyses (TGA) were performed to determine the temperatures for asphaltene treatment without losing a significant mass of the sample. In each run, the mass of the samples used was less than $5 \mathrm{mg}$ to avoid any diffusion effect for this case. TGA for Asf12 sample was performed under air and $\mathrm{N}_{2}$ atmospheres from 373 to $1073 \mathrm{~K}$ at a heating rate of $20 \mathrm{~K} / \mathrm{min}$ to determine the oxidation temperatures. Asphaltenes samples were evaluated under air atmosphere for $5 \mathrm{~h}$ and isothermal conditions at defined temperatures of 373 and $473 \mathrm{~K}$. Finally, Asf12 sample was subjected to different exposure times $(1,5$ and $10 \mathrm{~h})$, also under isothermal conditions of $473 \mathrm{~K}$. All runs were performed at a constant flow of $100 \mathrm{~mL} / \mathrm{min}$ in a Q50 Thermogravimetric Analyzer (TGA, TA Instruments, Inc., New Castle, DE, USA). A Fourier transform infrared (FTIR) spectrophotometer (IRAffinity, Shimadzu, Nakagyo-ku, Kyoto, Japan) was coupled with the TGA to follow the NOx subproducts (analyzed at $1550 \mathrm{~cm}^{-1}$ and $1365 \mathrm{~cm}^{-1}$ ) of asphaltene thermal treatment, which operates at a resolution of $2 \mathrm{~cm}^{-1}$ with 16 scans per minute in the range of 4000 to $400 \mathrm{~cm}^{-1}$. All experiments were performed in triplicate for confirming the reproducibility.

\subsubsection{FTIR of Solid Asphaltenes}

For Fourier transform infrared (FTIR) analysis [85], $\mathrm{KBr}$ was mixed with each sample of asphaltenes in a 30:1 weight ratio [86]. For samples detection, a $\mathrm{KCl}$ cell with a $0.25 \mathrm{~mm}$ spacing was used and placed in the FTIR at room temperature. The obtained FTIR spectra were analyzed using the OriginPro 2016 software (OriginLab Corporation, Northampton, MA, USA) and different indexes were calculated to provide qualitative information on asphaltenes molecules. Each measurement was performed in triplicate to ensure reproducibility of the measurements. All indexes were calculated based on areas related to specific bands from valley to valley and applying a deconvolution technique to avoid overlapping $[51,87,88]$. For example, the calculated area from the band at $1600 \mathrm{~cm}^{-1}$ is denoted as $\mathrm{A}_{1600}$. Brief descriptions of the calculated indexes are presented in Table S1 of the Supporting Information Document. 


\subsection{Preparation of Emulsions}

Emulsions were prepared with model solutions of untreated (without oxidation) and thermally treated asphaltene samples at 373 and $473 \mathrm{~K}$ with concentrations of 100, 500 and $1000 \mathrm{mg} / \mathrm{L}$ in toluene. Preparations were performed using three different model solutions to water volume ratios of 1:4, 1:1, and 4:1. For this, first, the asphaltenes were dissolved in toluene and constantly stirred at $300 \mathrm{rpm}$ for $24 \mathrm{~h}$. The complete solubility of asphaltenes was verified using an optical microscope Moticam 5 (Motic Instruments Inc., Carlsbad, CA, USA). After, deionized water was added, and the mixture was stirred at 14,000 rpm for $15 \mathrm{~min}$ at room temperature (298 K) using a Single-Spindle Mixer HMD200 Series (Hamilton Beach, Picton, ON, Canada) equipped-with a solid agitator, a $0.95 \mathrm{~L}$ stainless steel cup and a propeller impeller.

\subsection{Emulsions Characterization}

The characteristics of the emulsions were evaluated by phase identification, drop size of the dispersed phase, and interfacial tension measurements. Each phase of the system was quantified in volume to observe the effect of the asphaltene thermal treatment on the formation of $\mathrm{W} / \mathrm{O}$ and/or $\mathrm{O} / \mathrm{W}$ emulsions, as well as their stability. Phase volume was determined using $100 \mathrm{~mL}$ graduated test cylinders hermetically isolated at $298 \mathrm{~K}$ and atmospheric pressure. The volume of each phase was monitored, and measurements were conducted after $24 \mathrm{~h}$ when the system was found to be stable. For each phase, drop sizes were obtained using a rotating phase BA310 Trinocular microscope with Moticam 5 (Motic Instruments Inc., Carlsbad, CA, USA). The methodology used to obtain the drops mean size of dispersed phase depended on the number of drops and the mapped region. The method used to determine the population size consists of first fixing the drops population for each sample, setting the level of confidence $(95 \%)$, calculating the confidence interval, and then calculating the population size. The average size of the drops of the dispersed phase was calculated by using a statistical software MiniTab17 (Minitab Inc., State College, PA, USA) and the size obtained for each drop was measured using a morphometric software tpsDig 2.17 (SUNY, Stony Brook, NY, USA) [89]. Also, the measurements of interfacial tension (IFT) of the emulsions were carried out using a digital tensiometer (KRÜSS GmbH K20, Hamburg, Germany), using a Du Noüy ring [90] composed of platinum-iridium that is suspended from a force sensor. The instrument is first calibrated with a base fluid (water $\sim 72 \mathrm{mN} / \mathrm{m}$ ), and after each measurement, the ring is subjected to a temperature of $473 \mathrm{~K}$ for $5 \mathrm{~min}$ to remove impurities. For the IFT measurements, the oil and the brine systems where equilibrated for $24 \mathrm{~h}$. Surface tension measurement of toluene solutions of asphaltenes and a stirred mixture of solid asphaltene in water were measured to discard possible surface active impurities.

\section{Conclusions}

The effect of physicochemical changes in asphaltenes molecule after oxidation at $373 \mathrm{~K}$ and $473 \mathrm{~K}$ in the formation of water in model solutions emulsions was investigated. Compositional and structural changes in asphaltenes molecules after oxidation at 373 and $473 \mathrm{~K}$ were determined by elemental analyses, FTIR, solvency tests, and TGA. By increasing the temperature and exposure time to oxidation, the aliphatic compounds, $\mathrm{H} / \mathrm{C}$ ratio, sulfoxides groups, aliphatic chain lengths and ramifications are reduced. Conversely, the aromaticity and aromatic rings/aliphatic hydrogens ratio increased. The decrease in the N/C ratio suggests nitrogen oxidation and conversion to NOx.

The formation of $\mathrm{W} / \mathrm{O}$ emulsions is favored by the presence of functional groups which determine the orientation and adsorption of asphaltenes at the interface. Further, the interfacial film is reinforced, which lead to the inhibition of the droplets coalescence. In all cases evaluated, $\mathrm{W} / \mathrm{O}$ emulsions were more stable for oxidized samples than for the untreated ones. The increase in the oxidation temperature helps to stabilize the $\mathrm{W} / \mathrm{O}$ emulsions and inhibit the formation of $\mathrm{O} / \mathrm{W}$ emulsions. Increasing the concentration of asphaltenes in the $\mathrm{W} / \mathrm{O}$ system leads to lower droplet size, i.e., more stable emulsions are obtained. It was obtained that the stabilization of emulsions after asphaltene undergo oxidation is 
improved by higher temperatures and higher exposure times to oxidation. Also, IFT measurements revealed that no carboxylic acids are formed in the oxidation process and is discarded as the main emulsification mechanism. Possible transformations product of the oxidation process are of special interest due to the nitrogen removal prevails among them. Future works should include the effect of the resins transformation in the emulsification process and how they change the rheological behavior of the emulsifier system.

This work pays particular attention to thermal processes for EOR operations and could lead to the design of technologies to inhibit this problem in field applications.

Supplementary Materials: The following are available online at http:/ / www.mdpi.com/1996-1073/11/4/722/s1, Figure S1: Thermogravimetric analysis of asphaltene decomposition under oxidative and inert atmospheres; Table S1: Indexes defined transmittance bands FTIR for structural characterization of $n-C_{7}$ asphaltenes; Figure S2: Qualitative compositional indexes of oxidized asphaltenes at different temperatures (Asf12, Asf12/373 and Asf12/473) from FTIR spectra: (a) Aromaticity Index, (b) Aliphatic index, (c) Branching of aliphatic chains, (d) Carbonyl groups, (e) Sulfoxide groups, (f) Length of aliphatic chains, (g) $\mathrm{CH}_{2} / \mathrm{CH}_{3}$ ratio and (h) Aar/Aal ratio; Figure S3: Qualitative structural indexes of asphaltenes (Asf12/473) oxidized at different exposure times: (a) aromaticity index, (b) aliphatic index, (c) branching of aliphatic chains, (d) Carbonyl groups, (e) Sulfoxides groups, (f) Length of aliphatic chains, (g) $\mathrm{CH}_{2} / \mathrm{CH}_{3}$ ratio and (h) Aar/Aal ratio.

Acknowledgments: The authors acknowledge Departamento Administrativo de Ciencia, Tecnología e Innovación (COLCIENCIAS), and Agencia Nacional de Hidrocarburos (Colombia) for their support provided through the 272-2017 agreement. They also acknowledge the Universidad Nacional de Colombia for logistical and financial support.

Author Contributions: All authors conceived and designed the experiments, analyzed the data, contributed reagents/materials/analysis tools, and wrote/revised the paper.

Conflicts of Interest: The authors declare no conflict of interest.

\section{References}

1. Alboudwarej, H.; Felix, J.; Taylor, S.; Badry, R.; Bremner, C.; Brough, B.; Skeates, C.; Baker, A.; Palmer, D.; Pattison, K. Highlighting heavy oil. Oilfield Rev. 2006, 18, 34-53.

2. Mullins, O.C. The asphaltenes. Annu. Rev. Anal. Chem. 2011, 4, 393-418. [CrossRef] [PubMed]

3. Clark, H.P.; Ascanio, F.A.; Van Kruijsdijk, C.P.; Chavarria, J.L.; Zatka, M.J.; Williams, W.; Yahyai, A.H.; Shaw, J.D.; Bedry, M. Method to Improve Thermal EOR Performance Using Intelligent Well Technology: Orion SAGD Field Trial. In Proceedings of the Canadian Unconventional Resources and International Petroleum Conference, Calgary, AB, Canada, 19-21 October 2010; Society of Petroleum Engineers: Richardson, TX, USA, 2010.

4. Al Adasani, A.; Bai, B. Analysis of EOR projects and updated screening criteria. J. Pet. Sci. Eng 2011, 79, 10-24. [CrossRef]

5. Wei, L.; Zhu, J.-H.; Qi, J.-H. Application of nano-nickel catalyst in the viscosity reduction of Liaohe extra-heavy oil by aqua-thermolysis. J. Fuel Chem. Technol. 2007, 35, 176-180.

6. Zabala, R.; Franco, C.; Cortés, F. Application of Nanofluids for Improving Oil Mobility in Heavy Oil and Extra-Heavy Oil: A Field Test. In Proceedings of the SPE Improved Oil Recovery Conference, Tulsa, OK, USA, 11-13 April 2016; Society of Petroleum Engineers: Richardson, TX, USA, 2016.

7. Pereira, J.S.; Mello, P.A.; Moraes, D.P.; Duarte, F.A.; Dressler, V.L.; Knapp, G.; Flores, É.M. Chlorine and sulfur determination in extra-heavy crude oil by inductively coupled plasma optical emission spectrometry after microwave-induced combustion. Spectrochim. Acta Part B 2009, 64, 554-558. [CrossRef]

8. Hong, C.; Kishita, A.; Watanabe, T.; Enomoto, H. Formation mechanism of emulsion in in-situ combustion and physical model for in-situ combustion. J. Jpn. Assoc. Pet. Technol. 1998, 63, 251-257. [CrossRef]

9. Bennion, D.B. An overview of formation damage mechanisms causing a reduction in the productivity and injectivity of oil and gas producing formations. J. Can. Pet. Technol. 2002, 41. [CrossRef]

10. Mandal, A.; Samanta, A.; Bera, A.; Ojha, K. Characterization of Oil-Water Emulsion and Its Use in Enhanced Oil Recovery. Ind. Eng. Chem. Res. 2010, 49, 12756-12761. [CrossRef]

11. Uzoigwe, A.; Marsden, S., Jr. Emulsion Rheology and Flow through Unconsolidated Synthetic Porous Media. In Proceedings of the Fall Meeting of the Society of Petroleum Engineers of AIME, Houston, TX, USA, 4-7 October 1970; Society of Petroleum Engineers: Richardson, TX, USA, 1970. 
12. Moore, R.; Laureshen, C.; Mehta, S.; Ursenbach, M. Observations and design considerations for in situ combustion projects. J. Can. Pet. Technol. 1999, 38. [CrossRef]

13. Cheih, C. State-of-the-art review of fireflood field projects (includes associated papers 10901 and 10918). J. Pet. Technol. 1982, 34, 19-36. [CrossRef]

14. Burger, J.G. Chemical aspects of in-situ combustion-heat of combustion and kinetics. Soc. Pet. Eng. J. 1972, 12, 410-422. [CrossRef]

15. Kang, W.; Xu, B.; Wang, Y.; Li, Y.; Shan, X.; An, F.; Liu, J. Stability mechanism of W/O crude oil emulsion stabilized by polymer and surfactant. Colloids Surf. A 2011, 384, 555-560. [CrossRef]

16. Bobra, M. A Study of the Formation of Water-in-Oil Emulsions. In Proceedings of the Thirteenth Arctic and Marine Oilspill Program Technical Seminar, Edmonton, AB, Canada, 6-8 June 1990; pp. 6-8.

17. Kokal, S.L. Crude oil emulsions: A state-of-the-art review. SPE Prod. Facil. 2005, 20, 5-13. [CrossRef]

18. Mandal, A.; Bera, A. Modeling of flow of oil-in-water emulsions through porous media. Pet. Sci. 2015, 12, 273-281. [CrossRef]

19. Ortiz, D.; Baydak, E.; Yarranton, H. Effect of surfactants on interfacial films and stability of water-in-oil emulsions stabilized by asphaltenes. J. Colloid Interface Sci. 2010, 351, 542-555. [CrossRef] [PubMed]

20. Morales Corozo, J.R. Estudio del comportamiento reológico de emulsiones de crudos pesados. Tesis de Grado para la obtención del Título de Ingeniero Químico. 2014. Carrera de Ingeniería Química. Quito: UCE. 75 p. Available online: http:/ / www.dspace.uce.edu.ec/bitstream/25000/2776/1/T-UCE-0017-65.pdf (accessed on 3 February 2018).

21. Kokal, S.; Al-Juraid, J. Quantification of Various Factors Affecting Emulsion Stability: Watercut, Temperature, Shear, Asphaltene Content, Demulsifier Dosage and Mixing Different Crudes. In Proceedings of the SPE Annual Technical Conference and Exhibition, Houston, TX, USA, 3-6 October 1999; Society of Petroleum Engineers: Richardson, TX, USA, 1999.

22. Spiecker, P.M.; Gawrys, K.L.; Kilpatrick, P.K. Aggregation and solubility behavior of asphaltenes and their subfractions. J. Colloid Interface Sci. 2003, 267, 178-193. [CrossRef]

23. Kilpatrick, P.K.; Spiecker, P.M. Asphaltene Emulsions; Marcel Dekker: New York, NY, USA, 2001; Volume 3, pp. 707-730.

24. Tambe, D.E.; Sharma, M.M. The effect of colloidal particles on fluid-fluid interfacial properties and emulsion stability. Adv. Colloid Interface Sci. 1994, 52, 1-63. [CrossRef]

25. Rane, J.P.; Harbottle, D.; Pauchard, V.; Couzis, A.; Banerjee, S. Adsorption kinetics of asphaltenes at the oil-water interface and nanoaggregation in the bulk. Langmuir 2012, 28, 9986-9995. [CrossRef] [PubMed]

26. Rane, J.P.; Pauchard, V.; Couzis, A.; Banerjee, S. Interfacial rheology of asphaltenes at oil-water interfaces and interpretation of the equation of state. Langmuir 2013, 29, 4750-4759. [CrossRef] [PubMed]

27. Rane, J.P.; Zarkar, S.; Pauchard, V.; Mullins, O.C.; Christie, D.; Andrews, A.B.; Pomerantz, A.E.; Banerjee, S. Applicability of the Langmuir Equation of State for asphaltene adsorption at the oil-water interface: Coal-derived, petroleum and synthetic asphaltenes. Energy Fuels 2015, 29, 3584-3590. [CrossRef]

28. Pauchard, V.; Rane, J.P.; Zarkar, S.; Couzis, A.; Banerjee, S. Long-Term Adsorption Kinetics of Asphaltenes at the Oil-Water Interface: A Random Sequential Adsorption Perspective. Langmuir 2014, 30, 8381-8390. [CrossRef] [PubMed]

29. McLean, J.D.; Kilpatrick, P.K. Effects of asphaltene solvency on stability of water-in-crude-oil emulsions. J. Colloid Interface Sci. 1997, 189, 242-253. [CrossRef]

30. Yarranton, H.W.; Hussein, H.; Masliyah, J.H. Water-in-hydrocarbon emulsions stabilized by asphaltenes at low concentrations. J. Colloid Interface Sci. 2000, 228, 52-63. [CrossRef] [PubMed]

31. Xia, L.; Lu, S.; Cao, G. Stability and demulsification of emulsions stabilized by asphaltenes or resins. J. Colloid Interface Sci. 2004, 271, 504-506. [CrossRef] [PubMed]

32. Ancheyta, J.; Centeno, G.; Trejo, F.; Marroquin, G. Changes in asphaltene properties during hydrotreating of heavy crudes. Energy Fuels 2003, 17, 1233-1238. [CrossRef]

33. AlHumaidan, F.S.; Hauser, A.; Rana, M.S.; Lababidi, H.M. Impact of Thermal Treatment on Asphaltene Functional Groups. Energy Fuels 2016, 30, 2892-2903. [CrossRef]

34. Moschopedis, S.; Speight, J. Oxidative degradation of Athabasca asphaltenes. Fuel 1971, 50, $211-217$. [CrossRef]

35. Gonzalez, L.; Ferrer, J.; Fuenmayor, M.; Castillo, N.; Gil, E.; Farouq Ali, S. Use of Reservoir Simulation to Estimate Drainage Area and Recovery Factor of an In-Situ Combustion Project in a Complex Water-Drive 
Heavy Oil Reservoir. In Proceedings of the SPE Heavy Oil Conference-Canada, Calgary, AB, Canada, 10-12 June 2014; Society of Petroleum Engineers: Richardson, TX, USA, 2014.

36. Orea, M.; Bruzual, J.; Diaz, A.; Árraga, T.; Benítez, N.; Castillo, J. Formation of stable emulsions under in-situ combustion conditions: An assessment of the injected gas-crude oil-water-rock interplay in Quifa oilfield, Los Llanos Basin, Colombia. J. Pet. Sci. Eng. 2017, 159, 103-114. [CrossRef]

37. Prieto, H.; Lima, E.; Gaviria, M.; Gil, E.; Benitez, N.; Fuenmayor, M. Design and Operation of Production Facilities of the Quifa Field In-situ Combustion Project. In Proceedings of the SPE Annual Technical Conference and Exhibition, Houston, TX, USA, 28-30 September 2015; Society of Petroleum Engineers: Richardson, TX, USA, 2015.

38. Franco, C.A.; Montoya, T.; Nassar, N.N.; Pereira-Almao, P.; Cortés, F.B. Adsorption and subsequent oxidation of colombian asphaltenes onto Nickel and/or Palladium oxide supported on fumed silica nanoparticles. Energy Fuels 2013, 27, 7336-7347. [CrossRef]

39. Nassar, N.N.; Hassan, A.; Pereira-Almao, P. Comparative oxidation of adsorbed asphaltenes onto transition metal oxide nanoparticles. Colloids Surfaces A 2011, 384, 145-149. [CrossRef]

40. Nassar, N.N.; Hassan, A.; Pereira-Almao, P. Metal oxide nanoparticles for asphaltene adsorption and oxidation. Energy Fuels 2011, 25, 1017-1023. [CrossRef]

41. Habib, F.K.; Diner, C.; Stryker, J.M.; Semagina, N.; Gray, M.R. Suppression of addition reactions during thermal cracking using hydrogen and sulfided iron catalyst. Energy Fuels 2013, 27, 6637-6645. [CrossRef]

42. Alshareef, A.H.; Scherer, A.; Tan, X.; Azyat, K.; Stryker, J.M.; Tykwinski, R.R.; Gray, M.R. Formation of archipelago structures during thermal cracking implicates a chemical mechanism for the formation of petroleum asphaltenes. Energy Fuels 2011, 25, 2130-2136. [CrossRef]

43. Curtis, C.W.; Jeon, Y.W.; Clapp, D.J. Adsorption of asphalt functionalities and oxidized asphalts on aggregate surfaces. Fuel Sci. Technol. Int. 1989, 7, 1225-1268. [CrossRef]

44. Moreno, L.S.; Babadagli, T. Quantitative and Visual Characterization of Asphaltenic Components of Heavy-Oil and Bitumen Samples after Solvent Interaction at Different Temperatures and Pressures. In Proceedings of the SPE International Symposium on Oilfield Chemistry, The Woodlands, TX, USA, 8-10 April 2013; Society of Petroleum Engineers: Richardson, TX, USA, 2013.

45. Rojas-González, A.F.; Barraza-Burgos, J.M. Efecto de la relación atómica oxígeno/carbono del carbón sobre la reactividad en la combustión de carbonizados. Ing. Univ. 2013, 17, 41-57.

46. Hosseinpour, N.; Khodadadi, A.A.; Bahramian, A.; Mortazavi, Y. Asphaltene adsorption onto acidic/basic metal oxide nanoparticles toward in situ upgrading of reservoir oils by nanotechnology. Langmuir 2013, 29, 14135-14146. [CrossRef] [PubMed]

47. Hosseinpour, N.; Mortazavi, Y.; Bahramian, A.; Khodatars, L.; Khodadadi, A.A. Enhanced pyrolysis and oxidation of asphaltenes adsorbed onto transition metal oxides nanoparticles towards advanced in-situ combustion EOR processes by nanotechnology. Appl. Catal. A Gen. 2014, 477, 159-171. [CrossRef]

48. Yan, C.; Yang, Y.; Liu, M.; Nie, M.; Zhou, J.L. Phenanthrene sorption to Chinese coal: Importance of coal's geochemical properties. J. Hazard. Mater. 2011, 192, 86-92. [CrossRef] [PubMed]

49. Acevedo, S.; Castro, A.; Vásquez, E.; Marcano, F.; Ranaudo, M.A. Investigation of physical chemistry properties of asphaltenes using solubility parameters of asphaltenes and their fractions A1 and A2. Energy Fuels 2010, 24, 5921-5933. [CrossRef]

50. Acevedo, S.; Escobar, O.; Echevarria, L.; Gutiérrez, L.B.; Méndez, B. Structural analysis of soluble and insoluble fractions of asphaltenes isolated using the PNP method. Relation between asphaltene structure and solubility. Energy Fuels 2004, 18, 305-311. [CrossRef]

51. Permanyer, A.; Douifi, L.; Lahcini, A.; Lamontagne, J.; Kister, J. FTIR and SUVF spectroscopy applied to reservoir compartmentalization: A comparative study with gas chromatography fingerprints results. Fuel 2002, 81, 861-866. [CrossRef]

52. Calemma, V.; Iwanski, P.; Nali, M.; Scotti, R.; Montanari, L. Structural characterization of asphaltenes of different origins. Energy Fuels 1995, 9, 225-230. [CrossRef]

53. Mojelsky, T.; Ignasiak, T.; Frakman, Z.; McIntyre, D.; Lown, E.; Montgomery, D.; Strausz, O. Structural features of Alberta oil sand bitumen and heavy oil asphaltenes. Energy Fuels 1992, 6, 83-96. [CrossRef]

54. Siddiqui, M.N. Alkylation and oxidation reactions of Arabian asphaltenes. Fuel 2003, 82, 1323-1329. [CrossRef] 
55. Callejas, M.; Martınez, M.; Blasco, T.; Sastre, E. Coke characterisation in aged residue hydrotreating catalysts by solid-state 13C-NMR spectroscopy and temperature-programmed oxidation. Appl. Catal. A Gen. 2001, 218, 181-188. [CrossRef]

56. Muhammad, A.B. Thermal evolution of aliphatic and aromatic moieties of asphaltenes from coals of different rank: Possible implication to the molecular architecture of asphaltenes. Chin. J. Geochem. 2015, 34, 422-430. [CrossRef]

57. Quintero, K.; López, L.; De Lima, L. Espectroscopía infrarroja con transformadas de Fourier-Reflectancia total atenuada (IRTF/RTA) aplicada a la caracterización de crudos y su relación con la gravedad API. Rev. Fac. Ing. Univ. Cent. Venezuela 2014, 29, 93-102.

58. Chang, C.-L.; Fogler, H.S. Stabilization of asphaltenes in aliphatic solvents using alkylbenzene-derived amphiphiles. 1. Effect of the chemical structure of amphiphiles on asphaltene stabilization. Langmuir 1994, 10, 1749-1757. [CrossRef]

59. Vlachos, N.; Skopelitis, Y.; Psaroudaki, M.; Konstantinidou, V.; Chatzilazarou, A.; Tegou, E. Applications of Fourier transform-infrared spectroscopy to edible oils. Anal. Chim. Acta 2006, 573, 459-465. [CrossRef] [PubMed]

60. Brangule, A.; Gross, K.A. Importance of FTIR spectra deconvolution for the analysis of amorphous calcium phosphates. In IOP Conference Series: Materials Science and Engineering; IOP Publishing: Bristol, UK, 2015.

61. Lee, D.G.; Noureldin, N.A. Effect of water on the low-temperature oxidation of heavy oil. Energy Fuels 1989, 3, 713-715. [CrossRef]

62. Adams, J.J. Asphaltene adsorption, a literature review. Energy Fuels 2014, 28, 2831-2856. [CrossRef]

63. Zarkar, S.; Pauchard, V.; Farooq, U.; Couzis, A.; Banerjee, S. Interfacial properties of asphaltenes at toluene-water interfaces. Langmuir 2015, 31, 4878-4886. [CrossRef] [PubMed]

64. Sjöblom, J.; Aske, N.; Auflem, I.H.; Brandal, Ø.; Havre, T.E.; Sæther, Ø.; Westvik, A.; Johnsen, E.E.; Kallevik, H. Our current understanding of water-in-crude oil emulsions: Recent characterization techniques and high-pressure performance. Adv. Colloid Interface Sci. 2003, 100, 399-473. [CrossRef]

65. Zhang, L.Y.; Lopetinsky, R.; Xu, Z.; Masliyah, J.H. Asphaltene monolayers at a toluene/water interface. Energy Fuels 2005, 19, 1330-1336. [CrossRef]

66. Lobato, M.; Pedrosa, J.; Hortal, A.; Martinez-Haya, B.; Lebron-Aguilar, R.; Lago, S. Characterization and Langmuir film properties of asphaltenes extracted from Arabian light crude oil. Colloids Surfaces A 2007, 298, 72-79. [CrossRef]

67. Fingas, M.; Fieldhouse, B. A Review of Knowledge on Water-in-oil Emulsions. In Proceedings of the 29. Arctic and Marine Oilspill Program (AMOP) Technical Seminar, Ottawa, ON, Canada, 6-8 June 2006.

68. Sztukowski, D.M.; Jafari, M.; Alboudwarej, H.; Yarranton, H.W. Asphaltene self-association and water-in-hydrocarbon emulsions. J. Colloid Interface Sci. 2003, 265, 179-186. [CrossRef]

69. Gafonova, O.V.; Yarranton, H.W. The stabilization of water-in-hydrocarbon emulsions by asphaltenes and resins. J. Colloid Interface Sci. 2001, 241, 469-478. [CrossRef]

70. Shi, C.; Zhang, L.; Xie, L.; Lu, X.; Liu, Q.; Mantilla, C.A.; van den Berg, F.G.; Zeng, H. Interaction mechanism of oil-in-water emulsions with asphaltenes determined using droplet probe AFM. Langmuir 2016, 32, 2302-2310. [CrossRef] [PubMed]

71. Andrews, A.B.; McClelland, A.; Korkeila, O.; Demidov, A.; Krummel, A.; Mullins, O.C.; Chen, Z. Molecular orientation of asphaltenes and PAH model compounds in Langmuir-Blodgett films using sum frequency generation spectroscopy. Langmuir 2011, 27, 6049-6058. [CrossRef] [PubMed]

72. Yarranton, H.W. Asphaltene Solubility and Asphaltene Stabilized Water-in-Oil Emulsions. Ph.D. Thesis, University of Alberta, Edmonton, AB, Canada, 1997.

73. Fan, Y.; Simon, S.; Sjöblom, J. Influence of nonionic surfactants on the surface and interfacial film properties of asphaltenes investigated by Langmuir balance and Brewster angle microscopy. Langmuir 2010, 26, 10497-10505. [CrossRef] [PubMed]

74. Rodriguez-Abreu, C.; Delgado-Linares, J.G.; Bullon, J. Properties of Venezuelan asphaltenes in the bulk and dispersed state. J. Oleo Sci. 2006, 55, 563-571. [CrossRef]

75. Delgado, J. Asfaltenos. Composición, Agregación, Precipitación. Laboratorio FIRP: Cuaderno FIRP 369. Universidad de los Andes: Mérida-Venezuela, Mexico, Unpublished work. 2006.

76. Khadim, M.A.; Sarbar, M.A. Role of asphaltene and resin in oil field emulsions. J. Pet. Sci. Eng. 1999, 23, 213-221. [CrossRef] 
77. Harbottle, D.; Chen, Q.; Moorthy, K.; Wang, L.; Xu, S.; Liu, Q.; Sjoblom, J.; Xu, Z. Problematic stabilizing films in petroleum emulsions: Shear rheological response of viscoelastic asphaltene films and the effect on drop coalescence. Langmuir 2014, 30, 6730-6738. [CrossRef] [PubMed]

78. Petersen, J.C. Asphalt Oxidation-AH Overview Including a New Modelfor Oxidation Proposing that Physicochemical Factors Dominate the Oxidation Kinetics. Fuel Sci. Technol. Int. 1993, 11, 57-87. [CrossRef]

79. Shi, H.; Xu, T.; Zhou, P.; Jiang, R. Combustion properties of saturates, aromatics, resins, and asphaltenes in asphalt binder. Constr. Build. Mater. 2017, 136, 515-523. [CrossRef]

80. Mendez, Z.; Anton, R.E.; Salager, J.-L. Surfactant-oil-water systems near the affinity inversion. Part XI. pH sensitive emulsions containing carboxylic acids. J. Dispers. Sci. Technol. 1999, 20, 883-892. [CrossRef]

81. Saien, J.; Akbari, S. Interfacial tension of toluene+ water+ sodium dodecyl sulfate from (20 to 50) $\mathrm{C}$ and $\mathrm{pH}$ between 4 and 9. J. Chem. Eng. Data 2006, 51, 1832-1835. [CrossRef]

82. Nassar, N.N. Asphaltene adsorption onto alumina nanoparticles: Kinetics and thermodynamic studies. Energy Fuels 2010, 24, 4116-4122. [CrossRef]

83. Franco, C.A.; Nassar, N.N.; Ruiz, M.A.; Pereira-Almao, P.; Cortés, F.B. Nanoparticles for inhibition of asphaltenes damage: Adsorption study and displacement test on porous media. Energy Fuels 2013, 27, 2899-2907. [CrossRef]

84. Nadkarni, R. Guide to ASTM Test Methods for the Analysis of Petroleum Products and Lubricants; ASTM International West Conshohocken: Conshohocken, PA, USA, 2007.

85. Franco, C.A.; Lozano, M.M.; Acevedo, S.; Nassar, N.N.; Cortés, F.B. Effects of Resin I on Asphaltene Adsorption onto Nanoparticles: A Novel Method for Obtaining Asphaltenes/Resin Isotherms. Energy Fuels 2015, 30, 264-272. [CrossRef]

86. Franco, C.; Martínez, M.; Benjumea, P.; Patiño, E.; Cortés, F. Water Remediation Based on Oil Adsorption Using Nanosilicates Functionalized with a Petroleum Vacuum Residue. Adsorpt. Sci. Technol. 2014, 32, 197-208. [CrossRef]

87. Peeri, N.; Kister, J.; Quoniam, L.; Planche, J.; Germanaud, L. Assessment of Asphalt Rheological Behaviors by Studying Their Aromatic Structures. Polycycl. Aromat. Compd. 1996, 9, 29-36. [CrossRef]

88. Lamontagne, J.; Dumas, P.; Mouillet, V.; Kister, J. Comparison by Fourier transform infrared (FTIR) spectroscopy of different ageing techniques: Application to road bitumens. Fuel 2001, 80, 483-488. [CrossRef]

89. Rohlf, F. tpsDig 2.17, digitize landmarks and outlines, Morphometric software distributed via the Stony Brook Morphometrics. State University of New York at Stony Brook: New York, NY, USA, Unpublished work. 2013.

90. Aveyard, R.; Binks, B.; Fletcher, P.; Ye, X.; Lu, J. The resolution of emulsions, including crude oil emulsions, in relation to HLB behaviour. In Emulsions-A Fundamental and Practical Approach; Kluwer Academic Publishers: Dordrecht, The Netherlands, 1992; pp. 97-110. 